\title{
1 Identifying genomic regions and candidate genes selected during the breeding of rice in Vietnam
}

3 Janet Higgins ${ }^{1}$, Bruno Santos ${ }^{2}$, Tran Dang Khanh ${ }^{3,4}$, Khuat Huu Trung ${ }^{3}$, Tran Duy Duong ${ }^{3}$, Nguyen Thi Phuong

4 Doai ${ }^{3}$, Anthony Hall ${ }^{1}$, Sarah Dyer $^{2}$, Le Huy Ham ${ }^{3}$, Mario Caccamo ${ }^{2}$, Jose De Vega*1

5

$6 \quad{ }^{1}$ Earlham Institute, Norwich Research Park, Norwich, NR4 7UZ, UK.

$7 \quad{ }^{2}$ NIAB, 93 Lawrence Weaver Road, Cambridge, CB3 OLE, UK.

$8{ }^{3}$ Agriculture Genetics Institute (AGI), Hanoi, Vietnam.

$9 \quad{ }^{4}$ Vietnam National University of Agriculture, Hanoi, 131000, Vietnam.

10

$11 *$ Correspondence to jose.devega@earlham.ac.uk; Earlham Institute, Norwich Research Park, Norwich, NR4

12 7UZ, UK.

13 


\section{Key Message}

15 We localised regions in the rice genome selected during breeding by comparing allele frequency patterns among

16 Vietnamese rice subpopulations. We characterised candidate genes in the Indica-5 subpopulation with breeding

17 potential.

18

19 Abstract

20 Background and aims

21 Vietnam harnesses a rich diversity of rice landraces adapted to a broad range of conditions, which constitute a

22 largely untapped source of genetic diversity for the continuous improvement of rice cultivars. We previously

23 identified a strong population structure in Vietnamese rice, which is captured in five Indica and four Japonica

24 subpopulations, including an outlying Indica-5 group. Here, we leveraged on that strong differentiation, and the

25672 rice genomes generated, to identify genes within genomic regions putatively selected during domestication

26 and breeding of rice in Vietnam.

27 Methodology

28 We identified significant distorted patterns in allele frequency (XP-CLR method) and population differentiation

29 scores $\left(\mathrm{F}_{\mathrm{ST}}\right)$, resulting from differential selective pressures between native subpopulations, and compared them

30 with QTLs previously identified by GWAS in the same panel. We particularly focused on the outlying Indica-5

31 subpopulation because of its likely novelty and differential evolution.

32 Results

33 We identified selection signatures in each of the Vietnamese subpopulations and carried out a comprehensive

34 annotation of the 52 regions selected in Indica-5, which represented $8.1 \%$ of the rice genome. We annotated the

354,576 genes in these regions, verified the overlap with QTLs identified in the same diversity panel and the

36 comparison with a $\mathrm{F}_{\mathrm{ST}}$ analysis between subpopulations, to select sixty-five candidate genes as promising

37 breeding targets, several of which harboured alleles with non-synonymous substitutions.

38 Conclusions

39 Our results highlight genomic differences between traditional Vietnamese landraces, which are likely the

40 product of adaption to multiple environmental conditions and regional culinary preferences in a very diverse

41 country. We also verified the applicability of this genome scanning approach to identify potential regions

42 harbouring novel loci and alleles to breed a new generation of sustainable and resilient rice. 
bioRxiv preprint doi: https://doi.org/10.1101/2021.08.04.455072; this version posted August 5, 2021. The copyright holder for this preprint (which was not certified by peer review) is the author/funder, who has granted bioRxiv a license to display the preprint in perpetuity. It is made available under aCC-BY 4.0 International license.

44 KEYWORDS: Rice, breeding, selection, landraces

45 


\section{Introduction}

47 Vietnam harnesses a rich novel rice diversity due to the presence of native and traditional rice varieties adapted 48 to its broad latitudinal range, diversity of ecosystems and regional food preferences (Fukuoka et al. 2003). This diversity constitutes a largely untapped and highly valuable genetic resource for local and international breeding programs (Khanh et al. 2021). Vietnamese rice shows a strong population structure, which is captured within

51 five Indica and four Japonica subpopulations that we have recently described (Higgins et al. 2021). These

52 subpopulations were characterised in relation to the fifteen subpopulations of Asian rice described by the rice

53 3,000 rice genomes project (3K RGP) (Zhou et al. 2020). Among these nine populations described in Vietnam,

54 the Indica-5 (I5) subpopulation is an outlier and is expanded in Vietnam and, therefore, a potential source of novel variation compared to the wider Asian diversity.

Genetic variation and differentiation are influenced by natural processes, such as adaption and random drift, as well as conscious breeding selection and unconscious selection, due to the agricultural practices of local farmers. Selection causes detectable changes in allele frequencies at the selected sites and their flanking regions.

60 By modelling differences in allele frequency in close loci between neutrality and selection scenarios, the cross-

61 population composite likelihood ratio test (XP-CLR) can detect selective sweeps (Chen, Patterson, and Reich

62 2010). Any distorted pattern in allele frequency in contiguous SNP sites would have occurred too quickly (speed

63 of change is assessed over expanding windows based on the length of the affected region) to be explained by

64 random drift, so allowing the identification of selected regions. XP-CLR has been used to identify regions of

65 selection associated with domestication and improvement in a wide range of crops, such as apple (Duan et al.

66 2017), soybean (Zhou et al. 2015), cucumber (Qi et al. 2013) and wheat (Joukhadar et al. 2019); and has been

67 increasingly used in rice. Lyu et al.(2014) identified a list of differentiated genes that may account for the

68 phenotypic and physiological differences between upland and irrigated rice. Xie et al (2015) compared Indica

69 semi-dwarf modern bred varieties (IndII) with taller Chinese landraces (IndI) to identify signatures of rice

70 improvement and detected 200 regions spanning $7.8 \%$ of the genome. Meyer et al. (2016) identified genomic

71 regions associated with adaptive differentiation between O. glaberrima populations in Africa. He et al. (2017)

72 tested for positive selection between weedy and landrace rice using five different approaches. Cui et al. (2019)

73 identified potential selective sweeps in both Indica and Japonica genomes showing that there were multiple loci

74 responding to selection and that loci associated with agronomic traits were particularly targeted by selection. Lin

75 et al. (2020) used XP-CLR to demonstrate how introgressed regions were selected through hybrid rice breeding. 
76 While these studies were trying to answer difference questions, all used XP-CLR to detect selected regions. In addition, many of the studies used other metrics, such as the fixation index $\left(\mathrm{F}_{\mathrm{ST}}\right)$, to verify selected regions.

Here, we identified regions in the rice genome which have been selected by human breeding by leveraging the strong population structure among Vietnamese-native rice varieties and landraces, which has resulted from its diverse geography and agronomic practices. Unravelling the genomic differences and identifying regions selected between these nine subpopulations is the first step towards understanding their breeding potential. To assess the potential of our approach, we later focused on the outlying indica-5 (I5) subpopulation to identify candidate loci for breeding targets, since this subpopulation constitutes a gene-pool not used in rice improvement. To assess the putative role of these selected regions and whether these selected regions may contain loci that potentially could control agronomic traits, we looked for overlaps with previously mapped

87 QTLs in the same diversity panel, and regions enriched in gene ontology (GO) terms. QTLs have been described for a range of agronomic traits using the complete set of 672 native rice accessions (Higgins et al.

89 2021), while a subset of 182 of these traditional Vietnamese accessions (Phung 2014) were used for genome-

90 wide phenotype-genotype association studies (GWAS) relating to root development (Phung et al. 2016), panicle

91 architecture (Ta et al. 2018), drought tolerance (Hoang, Van Dinh, et al. 2019), leaf development (Hoang,

92 Gantet, et al. 2019), Jasmonate regulation (To et al. 2019) and phosphate starvation and efficiency (Mai et al.

93 2020; To et al. 2020). Finally, we studied alleles with non-synonymous substitutions in candidate genes in

94 selected regions of the outlying and highly selected I5 subpopulation.

\section{Materials and Methods}

\section{Sequencing and SNP calling and annotation}

98 A set of 616 Vietnamese samples were sequenced by us as described previously (Higgins et al. 2021). We added

9956 samples from the "3000 Rice Genomes Project" (3K RGP), which originated from Vietnam, to give a total of

100672 samples. These samples were genotyped as described previously (Higgins et al. 2021) to obtain a set of

101 imputed SNPs which were filtered to remove SNPs with excess heterozygosity, followed by filtering for a

102 minimal allele frequency of 5\%. We utilized a set of 2,027,294 SNPs for the 426 Indica samples and 1,125,716

103 SNPs for the 211 Japonica samples. Detailed information for each sample is available in Higgins et al. (2021). A

104 summary of the number and source of each subpopulation is available in Table 1 (47 Indica samples and 9

105 Japonica samples native to Vietnam were obtained from the 3K RGP project). The putative effects of the bi- 
106 allelic SNPs (low, medium and high effects) on the genome were determined using SnpEff (Cingolani et al.

107 2012) as detailed in Higgins et al. (2021) and the pre-built release 7.0 annotation from the Rice Genome

108 Annotation Project (http://rice.plantbiology. msu.edu/).

109

\section{Identification of selective sweeps using XP-CLR}

111 Selective sweeps across the genome were identified using XP-CLR (Chen, Patterson, and Reich 2010), a

112 method based on modelling the likelihood of multilocus allele frequency differentiation between two

113 populations. An updated version of the original code was used (https://github.com/hardingnj/xpclr). We used

$114100 \mathrm{kbps}$ sliding windows with a step size of $10 \mathrm{kbps}$ and the default option of a maximum of 200 SNPs in any

115 window. XP-CLR was run comparing the five Indica subpopulations to each other and the four Japonica

116 subpopulations to each other. Selected regions were extracted using the XP-CLR score for each $100 \mathrm{kbps}$

117 window as follows: 200 kbps centromeric regions were removed. The mean and 99th percentile of the XP-CLR

118 scores were calculated for each comparison between one subpopulation against the remaining ones (e.g. 15 vs

119 I1, I2, I3, I4). The mean $99^{\text {th }}$ percentile was used to define the cut-off level for selection in that subpopulation.

$120100 \mathrm{kbps}$ regions with an XP-CLR score higher than the cut-off were extracted and contiguous regions were

121 merged using BEDTools v2.26.0 (Quinlan and Hall 2010) specifying a maximum distance between regions of

$122100 \mathrm{kbps}$. Regions shorter than $80 \mathrm{kbps}$ were removed to give a final set of putatively selected regions for each

123 comparison. Putative regions observed selected in at least two comparisons for Japonica subpopulations, or

124 three comparisons for Indica subpopulations, were merged to obtain a final set of selected regions for each

125 subpopulation. BEDTools map was used for finding any overlap of selected regions with QTLs. QTL regions

126 using the same, or a subset of, the samples were previously identified by reviewing the literature. Genes lying

127 within the selected regions were extracted and checked for enrichment in Protein Domain and Pathway using a

128 maximum Bonferroni FDR value of 0.05 in PhytoMine (https://phytozome.jgi.doe.gov/), a service implemented

129 within Phytozome (Goodstein et al. 2012).

130

\section{Calculating $\mathbf{F}_{\text {ST }}$}

132 We calculated $\mathrm{F}_{\text {ST }}$ per SNP between the 43 samples in the I5 subpopulation and the 190 samples in the I2, I3

133 and I4 subpopulations with VCFtools using the "weir-fst-pop" option, which calculates $\mathrm{F}_{\mathrm{ST}}$ according to the

134 method of Weir and Cockerham (Weir and Cockerham 1984). Sites which are homozygous between these 
135 populations were removed, and negative values were changed to zero. The mean $\mathrm{F}_{\mathrm{ST}}$ was calculated per gene

136 and per specified region.

137

\section{Enrichment analysis of GO terms in selected regions}

139 The enrichment analysis was done with the library topGO (Alexa A 2010) in R, using as inputs the lists of genes

140 in each selected region, and the functional annotation of the rice genome (Rice MSU7.0) from agriGO

141 (http://bioinfo.cau.edu.cn/agriGO). The method in topGO compared the genes observed in each selected region

142 annotated with a given GO term with the expected number of genes annotated with that term in the whole

143 transcriptome. The statistical test was a F-Fisher test (FDR $\square<\square 0.05)$ with the "weight01" algorithm in topGO.

144 The "weight01" algorithm resolves the relations between related GO ontology terms at different levels. The

145 number of genes and selected regions that were enriched terms for the different subpopulations were plotted

146 using ggplot2 (Wickham 2016). 


\section{Results}

\section{Identification of selective sweeps among Vietnamese subpopulations}

150 To identify genomic regions that have been selected during the breeding of rice in Vietnam, we searched for

151 genomic regions with distorted patterns of allele frequency that cannot be explained by random drift using XP-

152 CLR (Chen, Patterson, and Reich 2010). We used our previously described dataset of 672 genomes from

153 Vietnamese-native landraces and varieties (Table 1), which have been divided into nine subpopulations (Higgins

154 2021). We compared all the five Indica subpopulations to each other and all the four Japonica subpopulations to

155 each other. Firstly, we obtained the mean XP-CLR score over the whole genome, as summarised in Table 2,

156 with the reciprocal differences in the comparisons between a pair of subpopulations in Supplementary Table S1.

157 Among the Japonica subpopulations, the J4 subpopulation had consistently the highest selection scores

158 especially against the J1 subpopulation. Among the Indica subpopulations, the I1 subpopulation had consistently

159 the lowest selection scores. The I5 subpopulation had the highest selection scores except in comparison with the

160 I3 subpopulation. We calculated the $99^{\text {th }}$ percentile for each comparison between a pair of subpopulations and

161 used the mean value for each subpopulation as a cut-off to identify selected regions (detailed in Supplementary

162 Table S2 and summarised in Table 3). We merged selected regions within 100kb of each other, so the final set

163 of selected regions for each comparison were of variable length. Selected regions covered a higher proportion of

164 the genome where the XP-CLR score was higher. The regions selected in the comparisons between a pair of

165 subpopulations were plotted along each chromosome for the Indica subpopulations (Supplementary Fig. S1) and

166 the Japonica subpopulations (Supplementary Fig. S2). In order to define a final set of selected regions in a given

167 subpopulation, we retained and merged regions selected in at least three comparisons between that

168 subpopulation and any other subpopulation in the case of the Indica ones, or in at least two comparisons in the

169 case of the Japonica subpopulations. This procedure is described in detail for the I5 subpopulation in a

170 subsequent section. The final set of selected regions in each subpopulation were plotted along each of the rice

171 chromosomes in Fig. 1A and 1B for the Indica and Japonica subtypes, respectively. The selected regions ranged

172 from 98,583 to $2,787,579$ bases for the Japonica subpopulations, and from 106,844 to 2,309,615 bases for the

173 Indica subpopulations. We observed slightly different patterns in length variation per subtype and subpopulation

174 (Supplementary Fig. S3). Overall, the Japonica subpopulations had fewer selected regions, which represented

175 from 3.7 to $4.9 \%$ of the genome, while Indica subpopulations ranged from 5.3 to $8.1 \%$ of the genome. Gene lists

176 for the selected regions are available in Supplementary Table S3. The Japonica subtypes had a higher proportion 
177 of long selected regions. These regions were confined to specific areas of the genome and absent from large

178 chromosome regions. All four Japonica subpopulations were selected on the long arm of chromosome 2 and in

179 both flanks of the centromeric region of chromosome 4. The selected regions in the Indica subpopulations were

180 spread throughout the genome and very variable in length. We particularly observed a high proportion of shorter

181 than average selected regions and a lower proportion of longer than average selected regions in the I1

182 subpopulation. The I5 subpopulation stands out as having the highest proportion of the genome under selection,

183 overlapping with the other landrace subpopulations (I2, I3 and I4) on the short arm of chromosome 1 and the

long arm of chromosome 9. However, selected regions in I5 were absent on the long arm of chromosome 4,

185 where all other landrace subpopulations overlapped with the elite I1 subpopulation.

\section{Putative roles of the regions under selection}

188 We looked for the overlap of the selected regions with sets of QTLs previously reported in the literature

189 (Supplementary Tables S4 and S5); 21 QTLs for basic plant and seed architecture traits identified using the

190 same complete set of Vietnamese rice samples (Higgins el al.2021); and 88 QTLs associated with root

191 development traits (Phung et al. 2016), 29 QTLs for panicle morphological traits (Ta et al. 2018), 17 QTLs for

192 tolerance to water deficit (Hoang, Van Dinh, et al. 2019), 13 QTLs for leaf mass traits (Hoang, Gantet, et al.

193 2019), 25 QTLs for growth mediated by jasmonate (To et al. 2019), 21 QTLs for phosphate starvation (Mai et

194 al. 2020) and 18 QTLs for phosphate efficiency (To et al. 2020) reported for a subset of 180 samples of the

195 whole dataset. The selected regions in the Japonica subpopulations had overlaps with all the QTLs sets, except

196 QTLs associated with growth regulation by jasmonate (Supplementary Table S5). The region on chromosome 2

197 that was selected in all Japonica subpopulations overlapped with a QTL for grain length (2_GL) and two related

198 QTLs for panicle morphology, secondary branch number (SBN) and spikelet number (SpN). These QTLs

199 collocate with osa-MIR437 (Ta et al. 2018), a monocot preferential miRNA that targets LOC_Os02g18080

200 (https://rapdb.dna.affrc.go.jp). J2 and J4 lowland varieties were both selected on the long arm of chromosome 5

201 and at the start of chromosome 9. The region on chromosome 5 overlaps with a QTL for drought sensitivity

202 observed after 4 weeks of drought stress (q4_Score4). The selected region on chromosome 9 overlaps with a

203 QTL for rachis length (RL), which is associated with the size of the panicle, a key component of yield. The

204 region towards the end of chromosome 11, which was selected in J1, J2 and J3, overlaps with qRTW11.19 as

205 well as several QTLs associated with root traits: Rq13_J_TIL, Rq29_J_DEPTH, Rq30_J_DEPTH,

206 Rq46_F_NCR, Rq63_J_THK. The selected regions in the Indica subtypes overlapped with all the QTL sets 
207 (Supplementary Table S4). Most overlaps that occurred in more than one subpopulation were also observed in

208 the I5 subpopulation, so are discussed in the next section. In addition, the region on the long arm of

209 chromosome 11, which is selected in both I3 and I4, overlaps with QTLs for drought sensitivity (Tq17 Score4),

210 rachis length (QTL25 RL) and response to jasmonate (qSHL5).

212 The total number of genes within the selected regions are shown in Table 2. For the Japonica subtypes, the

213 number of genes ranged from 2,007 genes within the selected regions of the $\mathrm{J} 3$ subpopulation to 2,643 genes

214 within the selected regions of the J4 subpopulation. For the Indica subtypes, the number of genes ranged from

2152,993 to 3,465 in the I1 to I4 subpopulations, whilst the I5 subpopulation had 4,576 genes within 52 selected

216 regions (gene listed in Supplementary Table S3). The overlap between genes selected in each subpopulation

217 showed that around half of the genes selected in a subpopulation were unique to that subpopulation

218 (Supplementary Fig. S4). No genes were selected in all subpopulations, but 230 genes were selected in all four

219 Japonica subpopulations, and 44 genes were selected in all the Indica landrace subpopulations I2 to I5.

221 An enrichment analysis of the GO terms enriched in each selected region was obtained by comparing the 222 annotations in each selected region with the whole genome annotation, as background (Supplementary Table

223 S6). The number of genes associated with enriched terms in different regions from the same subpopulation were 224 added up and plotted (Fig. 2). A large proportion of genes in selected regions were associated with the same 225 biological functions in the different Indica subpopulations, e.g. Lipid and protein metabolic process, or

226 "Biosynthetic process". However, we also evidenced specific selections in particular subpopulations, such as

227 "Photosynthesis" genes in $\mathrm{I} 5$ and $\mathrm{J} 1$; biotic response genes in $\mathrm{I} 2$, $\mathrm{I} 5$ and $\mathrm{J} 1$; abiotic response genes in $\mathrm{I} 1$ and $\mathrm{I} 5$;

228 and "flower development" genes in I2. Selected regions were more clearly associated to specific GO terms in

229 the Indica subpopulations than in the Japonica ones. The enrichment of GO terms was not correlated with the

230 total number of genes or genome length in each subpopulation (Supplementary Table S2).

\section{Selected regions in the outlying Indica-5 (I5) subpopulation}

233 Overall, the I5 subpopulation had the highest XP-CLR selection scores, this is reflected in I5 having the greatest 234 number of selected regions covering the highest proportion of the genome. I5 is an outlier subpopulation, which 235 contains a gene-pool not present the modern bred improved varieties that comprise subpopulation I1 (Higgins et 236 al 2021). The XP-CLR score of the I5 subpopulation compared to the other four Indica subpopulations in 100 
237 kbps windows is shown in Fig. 3. A cut-off XP-CLR score of 440 was used to defined selected regions in I5; I5

238 vs I1 produced 207 regions with a mean length of $267 \mathrm{kbp}$ (14.8\% of the genome); I5 vs I2 produced 120

239 regions with a mean length of $204 \mathrm{kbp}$ (6.57\% of the genome); I5 vs I3 produced 14 regions with a mean length

240 of $162 \mathrm{kbp}(0.61 \%$ of the genome); I5 vs I4 produced 122 regions with a mean length of $122 \mathrm{kbp}(6.02 \%$ of the

241 genome). Regions selected in three or more subpopulations were merged to give 52 selected regions in I5, the

242 regions are listed in Supplementary Table S7 and the functional annotation of each region detailed in

243 Supplementary Table S8. These regions had a mean length of $584 \mathrm{kbp}$, covered $30 \mathrm{Mbp}$, which represents

$2448.13 \%$ of the rice genome, and contained 4,576 genes (Supplementary Table S9). To gain further information on

245 the uniqueness of these 52 regions selected in I5, we calculated the $\mathrm{F}_{\mathrm{ST}}$ per SNP between the 43 samples in the

246 I5 subpopulation and the 190 samples in the landrace subpopulations, I2, I3 and I4. The variation of $\mathrm{F}_{\mathrm{ST}}$ and

247 diversity along each chromosome are shown in Fig. 3e and 3f. Both $\mathrm{F}_{\mathrm{ST}}$ and diversity varied widely along the

248 genome and did not show the clear peaks seen in the XP-CLR score, but peaks can be seen in $\mathrm{F}_{\mathrm{ST}}$ pattern

249 coinciding with XP-CLR peaks. This is clearest on chromosome 12 where $\mathrm{F}_{\mathrm{ST}}$ and XP-CLR score showed a

250 similar pattern and the diversity scores showing the opposite pattern. Our aim was to localise regions in the

251 genome with both high $\mathrm{F}_{\mathrm{ST}}$ between the I5 subpopulation compared to the other Vietnamese subpopulations and

252 low diversity in the $\mathrm{I} 5$ subpopulation. High $\mathrm{F}_{\mathrm{ST}}$ but low diversity would be expected in recently selected regions,

253 as can be seen on chromosome 10. Chromosome 3 also showed this pattern and contained a large number of

254 selected regions. The mean $\mathrm{F}_{\mathrm{ST}}$ per gene for the 4,576 genes selected in I5 is listed in Supplementary Table S10,

255 and the mean F $_{\text {ST }}$ per selected region is shown in Supplementary Table S7. The 1,983,066 heterozygous SNPs in

256 subpopulations I2, I3, I4 and I5 had a mean $\mathrm{F}_{\mathrm{ST}}$ of 0.185 , and this mean value increased to 0.305 for the subset

257 of 177,874 SNPs within the I5 selected regions.

258

259 The overlap of the 52 selected regions in the I5 subpopulation with the eight sets of QTLs is shown in Fig. 4.

260 Fourteen regions showed significant overlaps, these were shaded in Fig. 4 and listed in Table 4, detailing the

261 individual QTLs in Supplementary Table S11. Region 'a' was selected in I2, I4, I5, J1, J3 and J4, and coincided

262 with a QTL for spikelet number $(\mathrm{SpN})$ and two QTLs for root traits $(\mathrm{q} 73, \mathrm{q} 84)$ where the following candidate

263 genes LOC_Os01g10900, LOC_Os01g11010 and LOC_Os01g11860 were located. Region 'b' was selected in

264 I1 and I5, and coincided with a QTL for Leaf weight (FW_TW) and a QTL for relative phosphate uptake

265 (qRPUpE1.5) where the candidate gene LOC_Os01g66070 was located. Region 'c' was selected in I3 and I5

266 and overlapped a QTL for response of root length to jasmonate (qRTL1), an overlap of 37 candidate genes, 
267 including the transcription factor OsBLRI (LOC_Os02g47660), which regulates leaf angle in rice via

268 brassinosteroid signalling (Wang et al. 2020). Region 'd' partially overlapped a QTL for panicle length (9_PL)

269 and a region selected during recent domestication by farmers in China (Cui et al. 2019). Region 'e' fully overlapped a QTL for grain length (12_GL). Region 'f' was selected in I3, I4 and I5 and coincided with a QTL for leaf length (Rq2), which is only found in the Japonica subtype. Both regions 'e' and ' $\mathrm{f}$ ' overlapped with two large regions selected during recent domestication by farmers in China. Gene SSIIa (LOC_Os06g12450) and SDL/RNRS1 (LOC_Os06g14620) fall within this region. SSIIa is required for the edible quality of rice and plays an important role in grain starch synthesis (Zhang et al. 2011). SDL/RNRS1 (LOC_Os06g14620) encodes the small subunit of ribonucleotide reductase, which is required for chlorophyll synthesis and plant growth development (Qin et al. 2017). Region 'g' was selected in I1 and I5, and coincided with a QTL for panicle length (14_PL) and a QTL for maximum root length (Rq35). Region 'h' was selected in J4, I1 and I5, and coincided with a QTL for relative water content (Tq7) observed after 3 weeks of drought stress. Region ' $\mathrm{i}$ ' was selected in I3 and I5, and coincided with a QTL for root depth (Rq25). Region 'j' was selected in I3, I4 and I5, and overlapped with a QTL for response of shoot length to jasmonate (qSHL4) and 4 candidate genes, including a G2-like transcription factor (LOC_Os08g06370). Region ' $k$ ' was selected in I3, I4 and I5, and coincided with two QTLs for panicle traits, primary branch number (PBN) and primary branch average length

283 (PBL) that include the gene Auxin Response factor,OSPILS2 (LOC_Os08g09190). Region 'l' coincided with a 284 QTL for the number of crown roots in response to Pi deficiency (qNCR8.13), which contained two candidate genes, OsPP2C66 (LOC_Os08g39100) encoding PHOSPHATASE 2C, and transcription factor OsWKKY30 (LOC_Os08g38990). Region 'm' was selected in I1, I4 and I5, and coincided with four QTLs related to response of plants to drought (Tq12), which contained OsbZIP80 (LOC_Os11g05640), a transcription factor involved in dehydration stress response (Nijhawan et al. 2008). Region 'n' was selected in J1 and I5, and coincided with a QTL for number of crown roots (Rq43).

\section{Candidate genes and non-synonymous alleles in selected regions of I5}

292 We carried out three further analysis on the I5 subpopulation selected regions; a functional enrichment of the 293 genes found within the 52 regions (Supplementary Table S8), a detailed annotation of the 4,576 genes in the 52 294 regions selected in the I5 subpopulation (Supplementary Table S10), and an analysis of the location of twentyone genes with a putative role in salt tolerance in rice (Ganie et al. 2019) within the regions selected in the I5 
297 the previous three analysis were short-listed using the following criteria (Table 5, details in Supplementary

298 Table S13); $\mathrm{F}_{\mathrm{ST}}$ over 0.5 in the whole selected region or in the functionally enriched genes within regions,

299 presence of "High impact" SNPs, and presence of candidate genes from overlapping QTL. Ten of the 65 genes

300 contained SNPs classified using SnpEff as having a "High impact", i.e. predicted to cause deleterious gene

301 effects (five stop gains, two start loses and three frame swifts). The alleles of eight of the genes containing

302 "High impact" SNPs were different in the I5 subpopulation compared to the other Indica subpopulations (Fig. 5

303 and Supplementary Table S14). Among these eight genes, five of them showed the same allele than the Japonica

304 subpopulations. However, two genes (LOC_Os10g35604 and LOC_Os11g10070/OsSEU2) had alleles unique

305 to the I5 subpopulation.

306

\section{Discussion}

308 Vietnam has one of the richest rice germplasm resources with over 4000 years of rice-cultivating experience.

309 Local farmers have bred varieties to suit their ecosystem and regional culinary preferences. These conscious and

310 unconscious selection processes have resulted in detectable changes in allele frequencies at selected sites and

311 their flanking regions. We used a well-tested method, named XP-CLR, to identify distorted allele frequency

312 patterns in contiguous SNP sites that cannot be explained by random drift. To identify regions under selection,

313 we leveraged the strong population structure recently described in Vietnam (Higgins et al. 2021), which

314 comprised five Indica and four Japonica subpopulations of native rice accessions adapted to variable geography

315 and latitude range. We observed a stronger signature of selection in the Indica subtypes than in the Japonica

316 subtypes, which may reflect the higher diversity within the Indica subtypes in Vietnam. Taking into

317 consideration the size and diversity in each subpopulation (Higgins et al. 2021), the whole-genome XP-CLR

318 score was lower in the larger subpopulations (I1 and J1) and the subpopulations with the lower diversity.

319 However, this trend was not true in the subpopulation indica-5 (I5), which showed a higher selection score than

320 the other subpopulations with comparable size and diversity. Within the Indica subtypes, the subpopulation I5

321 showed the highest XP-CLR score against the subpopulation I1, which supports a strong signature for selection

322 in I5 compared to the modern bred varieties in I1. On the contrary, the lowest XP-CLR score was obtained when

323 I5 was compared to the I3 subpopulation, which is adapted to upland ecosystems (Phung et al. 2014). This

324 suggest I5 shares selection pressures and resilient traits with upland varieties. Intermediate XP-CLR scores were

325 obtained for the comparison of I5 with the two lowland subpopulations I2 (Mekong Delta) and I4 (Red River

326 Delta). 
328 Diversity is reduced when regions are under selection, but the observed diversity depends on many factors,

329 including how long ago the selection occurred and the type of alleles selected alongside. This is referred to as

330 the hitchhiking effect (Pavlidis and Alachiotis 2017). The fixation index $\left(\mathrm{F}_{\mathrm{ST}}\right)$ is a measure of population

331 differentiation due to genetic structure. Both measurements vary highly along the genome but can provide

332 additional information about the selected regions identified using XP-CLR. In this study, we calculated $\mathrm{F}_{\mathrm{ST}}$ by

333 comparing the I5 accessions to accessions in subpopulations I2, I3 and I4. We did not include the accessions in

334 the elite I1 subpopulation, as we are specifically interested in genes that have been selected during the breeding

335 of landraces within Vietnam. We used $\mathrm{F}_{\mathrm{ST}}$ as an additional measure for identifying regions and genes under

336 strong selection in the I5 subpopulation, and in support of the selection measurements obtained using XP-CLR.

338 Assigning functional roles to both regions and genes within the regions was the following natural step to

339 identify breeding targets. We used two approaches, overlap with QTLs and functional enrichment. Seven QTL

340 studies have been carried out on this dataset, finding associations for a range of traits relating to yield, this

341 enables us to propose functional associations for around a third of the selected regions. A functional enrichment

342 analysis evidenced selected regions were more clearly associated to specific GO terms in the Indica

343 subpopulations than in the Japonica ones. The enrichment of GO terms was not correlated with the total number

344 of genes or genome length in each subpopulation.

346 Looking in more detail at the 52 regions selected in the 15 subpopulation using a range of criteria, we identified

34765 candidate genes within 20 of the selected regions. Six of these regions had a mean $\mathrm{F}_{\mathrm{ST}}$ over 0.5 and we

348 highlighted the following candidate genes within these regions. In region I5_35, we identified the transcription

349 factor WOX11 involved in crown root development (Zhang et al. 2018) and OsCam1, OsbZIP63, and OsSDR,

350 which have putative roles in defence (Kim et al. 2009). Further genes of interest were (i) OsAAP6, a regulator of

351 grain protein content (Peng et al. 2014), in region I5_5, (ii) OSBSK3 (Zhang et al. 2016) and WSL5 (Liu et al.

352 2018), which play roles in growth, in region I5_29, (iii) OsABP, which is upregulated in response to multiple

353 abiotic stress treatments (Macovei et al. 2012), falls within region I5_33; and (iv) OsSFR6, a cold-responsive

354 gene (de Freitas et al. 2019), in region I5_47. In addition, eight of the ten genes containing "high impact"

355 mutations showed a different allelic content in the I5 subpopulation compared to the other Indica

356 subpopulations, and in six cases these alleles were similar to the Japonica ones. Two genes containing "high 
357 impact" mutations were OSFBX398, an F-box gene with a potential role in both abiotic and biotic stresses (Jain

358 et al. 2007; Vemanna et al. 2019), in region I5_49; and bip130 (Zhou et al. 2019) in region I5_30, which

359 regulates abscisic acid-induced antioxidant defence and fall within our QTL for panicle length (9_PL). In order

360 to pinpoint candidate genes for a range of agronomic traits, we looked for overlap of selected regions with

361 relevant QTLs. 14 of the 52 regions selected in the I5 subpopulation had overlaps with a wide range of QTLs,

362 two of most relevant genes in these regions were SSIIa, which is responsible for the eating quality of rice

363 (Zhang et al. 2011), and OsbZIP80, which is a transcription factor involved in dehydration stress response

364 (Nijhawan et al. 2008).

366 Finally, we looked for overlaps with selected genes identified in three published studies using XP-CLR in rice

367 (Lyu et al. 2014; Xie et al. 2015; Cui et al. 2019). Lyu et al. (2016) identified 56 Indica-specific genes in

368 selected regions, which may account for the phenotypic and physiological differences between upland and

369 irrigated rice. Thirty-one of these genes were on chromosome 3 and lied within regions also selected in the I4

370 and I5 subpopulations (I5_23, I5_24). The gene with the highest $\mathrm{F}_{\mathrm{ST}}$ (0.67) is ptr8 (LOC_Os03g51050), which

371 encodes a peptide transporter (Ouyang et al. 2010). Xie et al. (2015) identified 2,125 and 2,098 coding genes in

372 regions selected in the Chinese landraces (IndI) and modern-bred (IndII) subpopulations, respectively. We

373 evidenced an overlap of 131 genes in selected regions in the I5 subpopulation with the genes selected in the IndI

374 subpopulation and an overlap of 235 genes with the genes selected in the IndII subpopulation. This includes 7

375 genes in I5_22 and two genes in I5_23, both regions on chromosome 3, which were selected in all three

376 subpopulations. Cui et al (2018) identified 186 potential selective-sweep regions in the Indica subtypes, of

377 which 33 overlap with 9 of the 52 regions identified in the 15 subpopulation. These 9 regions contained 153

378 genes (Table 2). Cui et al. were specifically addressing the role of indigenous farmers in shaping the population

379 structure of rice landraces in China, there is the possibility that similar regions may also have been selected in

380 Vietnam. Substantial overlaps were found in three regions. On chromosome 2, 3 regions overlapped with I5_14.

381 On chromosome 6, 11 regions overlapped with I5_31 and I5_32, including gene SIIa (LOC_Os06g12450),

382 which is an important agronomic gene which is responsible for the eating quality of rice and plays an important

383 role in grain synthesis. On chromosome 9, 13 regions overlapped with I5_4, including gene LOC_Os09g28280,

384 which is a putative gibberellin receptor GID1L2 detailed in Table 2. 
386 XP-CLR has proved a valuable method for identifying regions selected in the Vietnamese rice subpopulations and provided an insight into how natural selection and agricultural practices of farmers in Vietnam have shaped

388 the population structure. Annotation of these regions with both overlaps with QTLs for a range of agronomic traits and functional enrichment allowed us to prioritise candidate regions as targets for breeding programs. Our

390 results give further support for the Indica I5 subpopulation being an important source of novel alleles for both national and international breeding programmes. Using a range of criteria, $\mathrm{F}_{\mathrm{ST}}$ and diversity in these regions, we

392 identified 65 genes which could be further investigated for their breeding potential.

393

394 Acknowledgements The author(s) acknowledge the support of the Biotechnology and Biological Sciences

395 Research Council (BBSRC), part of UK Research and Innovation; this research was funded by the BBSRC Core

396 Strategic Programme Grant (Genomes to Food Security) BB/CSP1720/1 and its constituent work package

397 BBS/E/T/000PR9818 (WP1 Signatures of Domestication and Adaptation); and BBSRC's grants

398 BB/N013735/1 (Newton Fund), and the Newton Fund Institutional Links (Project 172732508), which is 399 managed by the British Council.

400

401 Author contribution statement TDK, KHT, AH, SD, LHH, BS, MC and JDV designed and conceived the 402 research. JH performed the data analysis with assistance from JDV. JH and JDV wrote the paper. All authors 403 read and approved the final manuscript.

405 Availability of data All sequence data used in this manuscript have been deposited as study PRJEB36631 in the 406 European Nucleotide Archive.

408 Conflict of interest The authors declare that they have no conflicts of interest. 
Abbai, Ragavendran, Vikas Kumar Singh, Vishnu Varthini Nachimuthu, Pallavi Sinha, Ramchander Selvaraj, Abhilash Kumar Vipparla, Arun Kumar Singh, Uma Maheshwar Singh, Rajeev K. Varshney, and Arvind Kumar. 2019. 'Haplotype analysis of key genes governing grain yield and quality traits across $3 K$ RG panel reveals scope for the development of tailor-made rice with enhanced genetic gains', Plant Biotechnology Journal, 17: 1612-22.

Alexa A, Rahnenfuhrer J 2010. 'topGO: enrichment analysis for gene ontology. R package version 2.42.0. '.

Chen, H., N. Patterson, and D. Reich. 2010. 'Population differentiation as a test for selective sweeps', Genome Res, 20: 393-402.

Chen, R., Y. Cheng, S. Han, B. Van Handel, L. Dong, X. Li, and X. Xie. 2017. 'Whole genome sequencing and comparative transcriptome analysis of a novel seawater adapted, salt-resistant rice cultivar - sea rice 86', BMC Genomics, 18: 655.

Cingolani, P., A. Platts, L. Wang le, M. Coon, T. Nguyen, L. Wang, S. J. Land, X. Lu, and D. M. Ruden. 2012. 'A program for annotating and predicting the effects of single nucleotide polymorphisms, SnpEff: SNPs in the genome of Drosophila melanogaster strain w1118; iso-2; iso-3', Fly (Austin), 6: 80-92.

Cui, Di, Hongfeng Lu, Cuifeng Tang, Jinmei Li, Xinxiang A, Tengqiong Yu, Xiaoding Ma, Enlai Zhang, Yanjie Wang, Guilan Cao, Furong Xu, Yongli Qiao, Luyuan Dai, Ruiqiang Li, Shilin Tian, Hee-Jong Koh, and Longzhi Han. 2019. 'Genomic analyses reveal selection footprints in rice landraces grown under on-farm conservation conditions during a short-term period of domestication', Evolutionary Applications, 13: 290-302.

de Freitas, G. M., J. Thomas, R. Liyanage, J. O. Lay, S. Basu, V. Ramegowda, M. N. do Amaral, L. C. Benitez, E. J. Bolacel Braga, and A. Pereira. 2019. 'Cold tolerance response mechanisms revealed through comparative analysis of gene and protein expression in multiple rice genotypes', PLoS One, 14: e0218019.

Delteil, A., M. Blein, O. Faivre-Rampant, A. Guellim, J. Estevan, J. Hirsch, R. Bevitori, C. Michel, and J. B. Morel. 2012. 'Building a mutant resource for the study of disease resistance in rice reveals the pivotal role of several genes involved in defence', $\mathrm{Mol}$ Plant Pathol, 13: 72-82.

Du, H., L. Liu, L. You, M. Yang, Y. He, X. Li, and L. Xiong. 2011. 'Characterization of an inositol 1,3,4-trisphosphate 5/6-kinase gene that is essential for drought and salt stress responses in rice', Plant $\mathrm{Mol}$ Biol, 77: 547-63.

Duan, N., Y. Bai, H. Sun, N. Wang, Y. Ma, M. Li, X. Wang, C. Jiao, N. Legall, L. Mao, S. Wan, K. Wang, T. He, S. Feng, Z. Zhang, Z. Mao, X. Shen, X. Chen, Y. Jiang, S. Wu, C. Yin, S. Ge, L. Yang, S. Jiang, H. Xu, J. Liu, D. Wang, C. Qu, Y. Wang, W. Zuo, L. Xiang, C. Liu, D. Zhang, Y. Gao, Y. Xu, K. Xu, T. Chao, G. Fazio, H. Shu, G. Y. Zhong, L. Cheng, Z. Fei, and $X$. Chen. 2017. 'Genome re-sequencing reveals the history of apple and supports a two-stage model for fruit enlargement', Nat Commun, 8: 249.

Fukuoka, S., N. V. Alpatyeva, K. Ebana, N. T. Luu, and T. Nagamine. 2003. 'Analysis of Vietnamese rice germplasm provides an insight into Japonica rice differentiation', Plant Breeding, 122: 497-502.

Ganie, S. A., K. A. Molla, R. J. Henry, K. V. Bhat, and T. K. Mondal. 2019. 'Advances in understanding salt tolerance in rice', Theor Appl Genet, 132: 851-70. 
457

458

459

460

461

462

463

464

465

466

467

468

469

470

471

472

473

474

475

476

477

478

479

480

481

482

483

484

485

486

487

488

489

490

491

492

493

494

495

496

497

498

499

500

501

502

503

Goodstein, D. M., S. Shu, R. Howson, R. Neupane, R. D. Hayes, J. Fazo, T. Mitros, W. Dirks, U. Hellsten, N. Putnam, and D. S. Rokhsar. 2012. 'Phytozome: a comparative platform for green plant genomics', Nucleic Acids Res, 40: D1178-86.

Higgins, J., B. Santos, T. D. Khanh, K. H. Trung, T. D. Duong, N. T. P. Doai, N. T. Khoa, D. T. T. Ha, N. T. Diep, K. T. Dung, C. N. Phi, T. T. Thuy, N. T. Tuan, H. D. Tran, N. T. Trung, H. T. Giang, T. K. Nhung, C. D. Tran, S. V. Lang, T. Nghia, N. Van Giang, T. D. Xuan, A. Hall, S. Dyer, L. H. Ham, M. Caccamo, and J. J. De Vega. 2021. 'Resequencing of 672 Native Rice Accessions to Explore Genetic Diversity and Trait Associations in Vietnam', Rice (N Y), 14: 52.

Hoang, G. T., P. Gantet, K. H. Nguyen, N. T. P. Phung, L. T. Ha, T. T. Nguyen, M. Lebrun, B. Courtois, and X. H. Pham. 2019. 'Genome-wide association mapping of leaf mass traits in a Vietnamese rice landrace panel', PLoS One, 14: e0219274.

Hoang, G. T., L. Van Dinh, T. T. Nguyen, N. K. Ta, F. Gathignol, C. D. Mai, S. Jouannic, K. D. Tran, T. H. Khuat, V. N. Do, M. Lebrun, B. Courtois, and P. Gantet. 2019. 'Genomewide Association Study of a Panel of Vietnamese Rice Landraces Reveals New QTLS for Tolerance to Water Deficit During the Vegetative Phase', Rice (N Y), 12: 4.

https://github.com/hardingni/xpclr.

Jain, M., A. Nijhawan, R. Arora, P. Agarwal, S. Ray, P. Sharma, S. Kapoor, A. K. Tyagi, and J. P. Khurana. 2007. 'F-box proteins in rice. Genome-wide analysis, classification, temporal and spatial gene expression during panicle and seed development, and regulation by light and abiotic stress', Plant Physiol, 143: 1467-83.

Joukhadar, R., H. D. Daetwyler, A. R. Gendall, and M. J. Hayden. 2019. 'Artificial selection causes significant linkage disequilibrium among multiple unlinked genes in Australian wheat', Evol Appl, 12: 1610-25.

Khanh, Tran Dang, Vu Xuan Duong, Phi Cong Nguyen, Tran Dang Xuan, Nguyen Thanh Trung, Khuat Huu Trung, Dong Huy Gioi, Nguyen Huy Hoang, Hoang-Dung Tran, Do Minh Trung, and Bui Thi Thu Huong. 2021. 'Rice Breeding in Vietnam: Retrospects, Challenges and Prospects', Agriculture, 11.

Kim, E. H., Y. S. Kim, S. H. Park, Y. J. Koo, Y. D. Choi, Y. Y. Chung, I. J. Lee, and J. K. Kim. 2009. 'Methyl jasmonate reduces grain yield by mediating stress signals to alter spikelet development in rice', Plant Physiol, 149: 1751-60.

Kim, S. K., H. Y. Park, Y. H. Jang, K. C. Lee, Y. S. Chung, J. H. Lee, and J. K. Kim. 2016. 'OsNFYC2 and OsNF-YC4 proteins inhibit flowering under long-day conditions in rice', Planta, 243: 563-76.

Lira-Ruan, V., M. Ruiz-Kubli, and R. Arredondo-Peter. 2011. 'Expression of non-symbiotic hemoglobin 1 and 2 genes in rice (Oryza sativa) embryonic organs', Commun Integr Biol, 4: 457-8.

Liu, X., J. Lan, Y. Huang, P. Cao, C. Zhou, Y. Ren, N. He, S. Liu, Y. Tian, T. Nguyen, L. Jiang, and J. Wan. 2018. 'WSL5, a pentatricopeptide repeat protein, is essential for chloroplast biogenesis in rice under cold stress', J Exp Bot, 69: 3949-61.

Lombardo, F., M. Kuroki, S. G. Yao, H. Shimizu, T. Ikegaya, M. Kimizu, S. Ohmori, T. Akiyama, T. Hayashi, T. Yamaguchi, S. Koike, O. Yatou, and H. Yoshida. 2017. 'The superwoman1-cleistogamy 2 mutant is a novel resource for gene containment in rice', Plant Biotechnol J, 15: 97-106.

Lyu, J., B. Li, W. He, S. Zhang, Z. Gou, J. Zhang, L. Meng, X. Li, D. Tao, W. Huang, F. Hu, and W. Wang. 2014. 'A genomic perspective on the important genetic mechanisms of upland adaptation of rice', BMC Plant Biol, 14: 160. 
504

505

506

507

508

509

510

511

512

513

514

515

516

517

518

519

520

521

522

523

524

525

526

527

528

529

530

531

532

533

534

535

536

537

538

539

540

541

542

543

544

545

546

547

548

Macovei, A., N. Vaid, S. Tula, and N. Tuteja. 2012. 'A new DEAD-box helicase ATP-binding protein (OsABP) from rice is responsive to abiotic stress', Plant Signal Behav, 7: 113843.

Mai, N. T. P., C. D. Mai, H. V. Nguyen, K. Q. Le, L. V. Duong, T. A. Tran, and H. T. M. To. 2020. 'Discovery of new genetic determinants of morphological plasticity in rice roots and shoots under phosphate starvation using GWAS', J Plant Physiol, 257: 153340.

Mukherjee, S., S. Sengupta, A. Mukherjee, P. Basak, and A. L. Majumder. 2019. 'Abiotic stress regulates expression of galactinol synthase genes post-transcriptionally through intron retention in rice', Planta, 249: 891-912.

Nijhawan, A., M. Jain, A. K. Tyagi, and J. P. Khurana. 2008. 'Genomic survey and gene expression analysis of the basic leucine zipper transcription factor family in rice', Plant Physiol, 146: 333-50.

Ouyang, Jie, Zhaoyan Cai, Kuaifei Xia, Yaqing Wang, Jun Duan, and Mingyong Zhang. 2010. 'Identification and analysis of eight peptide transporter homologs in rice', Plant Science, 179: 374-82.

Park, S. H., P. J. Chung, P. Juntawong, J. Bailey-Serres, Y. S. Kim, H. Jung, S. W. Bang, Y. K. Kim, Y. Do Choi, and J. K. Kim. 2012. 'Posttranscriptional control of photosynthetic mRNA decay under stress conditions requires 3 ' and $5^{\prime}$ untranslated regions and correlates with differential polysome association in rice', Plant Physiol, 159: 1111-24.

Pavlidis, P., and N. Alachiotis. 2017. 'A survey of methods and tools to detect recent and strong positive selection', J Biol Res (Thessalon), 24: 7.

Peng, B., H. Kong, Y. Li, L. Wang, M. Zhong, L. Sun, G. Gao, Q. Zhang, L. Luo, G. Wang, W. Xie, J. Chen, W. Yao, Y. Peng, L. Lei, X. Lian, J. Xiao, C. Xu, X. Li, and Y. He. 2014. 'OsAAP6 functions as an important regulator of grain protein content and nutritional quality in rice', Nat Commun, 5: 4847.

Peng, X., H. Wang, J. C. Jang, T. Xiao, H. He, D. Jiang, and X. Tang. 2016. 'OsWRKY80OsWRKY4 Module as a Positive Regulatory Circuit in Rice Resistance Against Rhizoctonia solani', Rice (NY), 9: 63.

Phung, N. T., C. D. Mai, G. T. Hoang, H. T. Truong, J. Lavarenne, M. Gonin, K. L. Nguyen, T. T. Ha, V. N. Do, P. Gantet, and B. Courtois. 2016. 'Genome-wide association mapping for root traits in a panel of rice accessions from Vietnam', BMC Plant Biol, 16: 64.

Phung, N. T., C. D. Mai, P. Mournet, J. Frouin, G. Droc, N. K. Ta, S. Jouannic, L. T. Le, V. N. Do, P. Gantet, and B. Courtois. 2014. 'Characterization of a panel of Vietnamese rice varieties using DArT and SNP markers for association mapping purposes', BMC Plant Biol, 14: 371.

Qi, J., X. Liu, D. Shen, H. Miao, B. Xie, X. Li, P. Zeng, S. Wang, Y. Shang, X. Gu, Y. Du, Y. Li, T. Lin, J. Yuan, X. Yang, J. Chen, H. Chen, X. Xiong, K. Huang, Z. Fei, L. Mao, L. Tian, T. Stadler, S. S. Renner, S. Kamoun, W. J. Lucas, Z. Zhang, and S. Huang. 2013. 'A genomic variation map provides insights into the genetic basis of cucumber domestication and diversity', Nat Genet, 45: 1510-5.

Qin, R., D. Zeng, R. Liang, C. Yang, D. Akhter, M. Alamin, X. Jin, and C. Shi. 2017. 'Rice gene $\mathrm{SDL} / \mathrm{RNRS1}$, encoding the small subunit of ribonucleotide reductase, is required for chlorophyll synthesis and plant growth development', Gene, 627: 351-62.

Quinlan, A. R., and I. M. Hall. 2010. 'BEDTools: a flexible suite of utilities for comparing genomic features', Bioinformatics, 26: 841-2. 
Saeng-ngam, Sukhumaporn, Warintra Takpirom, Teerapong Buaboocha, and Supachitra Chadchawan. 2012. 'The role of the OsCam1-1 salt stress sensor in ABA accumulation and salt tolerance in rice', Journal of Plant Biology, 55: 198-208.

Sakamoto, T., H. Kitano, and S. Fujioka. 2017. 'Rice ERECT LEAF 1 acts in an alternative brassinosteroid signaling pathway independent of the receptor kinase OsBRI1', Plant Signal Behav, 12: e1396404.

Sumiyoshi, M., A. Nakamura, H. Nakamura, M. Hakata, H. Ichikawa, H. Hirochika, T. Ishii, S. Satoh, and H. Iwai. 2013. 'Increase in cellulose accumulation and improvement of saccharification by overexpression of arabinofuranosidase in rice', PLoS One, 8: e78269.

Ta, K. N., N. G. Khong, T. L. Ha, D. T. Nguyen, D. C. Mai, T. G. Hoang, T. P. N. Phung, I. Bourrie, B. Courtois, T. T. H. Tran, B. Y. Dinh, T. N. La, N. V. Do, M. Lebrun, P. Gantet, and S. Jouannic. 2018. 'A genome-wide association study using a Vietnamese landrace panel of rice (Oryza sativa) reveals new QTLs controlling panicle morphological traits', BMC Plant Biol, 18: 282.

Tanaka, W., T. Toriba, and H. Y. Hirano. 2017. 'Three TOB1-related YABBY genes are required to maintain proper function of the spikelet and branch meristems in rice', New Phytol, 215: 825-39.

To, H. T. M., K. Q. Le, H. Van Nguyen, L. V. Duong, H. T. Kieu, Q. A. T. Chu, T. P. Tran, and N. T. P. Mai. 2020. 'A genome-wide association study reveals the quantitative trait locus and candidate genes that regulate phosphate efficiency in a Vietnamese rice collection', Physiol Mol Biol Plants, 26: 2267-81.

To, H. T. M., H. T. Nguyen, N. T. M. Dang, N. H. Nguyen, T. X. Bui, J. Lavarenne, N. T. P. Phung, P. Gantet, M. Lebrun, S. Bellafiore, and A. Champion. 2019. 'Unraveling the Genetic Elements Involved in Shoot and Root Growth Regulation by Jasmonate in Rice Using a Genome-Wide Association Study', Rice (N Y), 12: 69.

Tu, Bin, Li Hu, Weilan Chen, Tao Li, Binhua Hu, Ling Zheng, Zheng Lv, Shuju You, Yuping Wang, Bingtian Ma, Xuewei Chen, Peng Qin, and Shigui Li. 2015. 'Disruption of OsEX070A1 Causes Irregular Vascular Bundles and Perturbs Mineral Nutrient Assimilation in Rice', Scientific Reports, 5: 18609.

Vemanna, R. S., R. Bakade, P. Bharti, M. K. P. Kumar, S. M. Sreeman, M. Senthil-Kumar, and U. Makarla. 2019. 'Cross-Talk Signaling in Rice During Combined Drought and Bacterial Blight Stress', Front Plant Sci, 10: 193.

Wang, K., M. Q. Li, Y. P. Chang, B. Zhang, Q. Z. Zhao, and W. L. Zhao. 2020. 'The basic helixloop-helix transcription factor OsBLR1 regulates leaf angle in rice via brassinosteroid signalling', Plant Mol Biol, 102: 589-602.

Weir, B. S., and C. Clark Cockerham. 1984. 'Estimating F-Statistics for the Analysis of Population Structure', Evolution, 38.

Wickham, H. 2016. 'ggplot2: elegant graphics for data analysis: Springer'.

Xie, W., G. Wang, M. Yuan, W. Yao, K. Lyu, H. Zhao, M. Yang, P. Li, X. Zhang, J. Yuan, Q. Wang, F. Liu, H. Dong, L. Zhang, X. Li, X. Meng, W. Zhang, L. Xiong, Y. He, S. Wang, S. Yu, C. Xu, J. Luo, X. Li, J. Xiao, X. Lian, and Q. Zhang. 2015. 'Breeding signatures of rice improvement revealed by a genomic variation map from a large germplasm collection', Proc Natl Acad Sci U S A, 112: E5411-9.

Yang, Sheng-hui, Xiang-li Niu, Di Luo, Chang-dong Chen, Xu Yu, Wei Tang, Bao-rong Lu, and Yong-sheng Liu. 2012. 'Functional Characterization of an Aldehyde Dehydrogenase Homologue in Rice', Journal of Integrative Agriculture, 11: 1434-44. 
596

597

598

599

600

601

602

603

604

605

606

607

608

609

610

611

612

613

614

615

616

617

618

619

620

621

622

623

624

625

626

627

628

629

630

631

632

633

634

635

636

637

638

639

640
Yi, J., S. R. Kim, D. Y. Lee, S. Moon, Y. S. Lee, K. H. Jung, I. Hwang, and G. An. 2012. 'The rice gene DEFECTIVE TAPETUM AND MEIOCYTES 1 (DTM1) is required for early tapetum development and meiosis', Plant J, 70: 256-70.

Ying, Y., W. Yue, S. Wang, S. Li, M. Wang, Y. Zhao, C. Wang, C. Mao, J. Whelan, and H. Shou. 2017. 'Two h-Type Thioredoxins Interact with the E2 Ubiquitin Conjugase PHO2 to Fine-Tune Phosphate Homeostasis in Rice', Plant Physiol, 173: 812-24.

Yu, M., C. P. Yau, and W. K. Yip. 2017. 'Differentially localized rice ethylene receptors OsERS1 and OsETR2 and their potential role during submergence', Plant Signal Behav, 12: e1356532.

Yuenyong, W., A. Chinpongpanich, L. Comai, S. Chadchawan, and T. Buaboocha. 2018. 'Downstream components of the calmodulin signaling pathway in the rice salt stress response revealed by transcriptome profiling and target identification', BMC Plant Biol, 18: 335.

Zang, D., H. Li, H. Xu, W. Zhang, Y. Zhang, X. Shi, and Y. Wang. 2016. 'An Arabidopsis Zinc Finger Protein Increases Abiotic Stress Tolerance by Regulating Sodium and Potassium Homeostasis, Reactive Oxygen Species Scavenging and Osmotic Potential', Front Plant Sci, 7: 1272.

Zhang, B., X. Wang, Z. Zhao, R. Wang, X. Huang, Y. Zhu, L. Yuan, Y. Wang, X. Xu, A. L. Burlingame, Y. Gao, Y. Sun, and W. Tang. 2016. 'OsBRI1 Activates BR Signaling by Preventing Binding between the TPR and Kinase Domains of OsBSK3 via Phosphorylation', Plant Physiol, 170: 1149-61.

Zhang, G., Z. Cheng, X. Zhang, X. Guo, N. Su, L. Jiang, L. Mao, and J. Wan. 2011. 'Double repression of soluble starch synthase genes SSIIa and SSIIIa in rice (Oryza sativa L.) uncovers interactive effects on the physicochemical properties of starch', Genome, 54: 448-59.

Zhang, T., R. Li, J. Xing, L. Yan, R. Wang, and Y. Zhao. 2018. 'The YUCCA-Auxin-WOX11 Module Controls Crown Root Development in Rice', Front Plant Sci, 9: 523.

Zhou, X., L. Ni, Y. Liu, and M. Jiang. 2019. 'Phosphorylation of bip130 by OsMPK1 regulates abscisic acid-induced antioxidant defense in rice', Biochem Biophys Res Commun, 514: 750-55.

Zhou, Y., D. Chebotarov, D. Kudrna, V. Llaca, S. Lee, S. Rajasekar, N. Mohammed, N. AlBader, C. Sobel-Sorenson, P. Parakkal, L. J. Arbelaez, N. Franco, N. Alexandrov, N. R. S. Hamilton, H. Leung, R. Mauleon, M. Lorieux, A. Zuccolo, K. McNally, J. Zhang, and R. A. Wing. 2020. 'A platinum standard pan-genome resource that represents the population structure of Asian rice', Sci Data, 7: 113.

Zhou, Z., Y. Jiang, Z. Wang, Z. Gou, J. Lyu, W. Li, Y. Yu, L. Shu, Y. Zhao, Y. Ma, C. Fang, Y. Shen, T. Liu, C. Li, Q. Li, M. Wu, M. Wang, Y. Wu, Y. Dong, W. Wan, X. Wang, Z. Ding, Y. Gao, H. Xiang, B. Zhu, S. H. Lee, W. Wang, and Z. Tian. 2015. 'Resequencing 302 wild and cultivated accessions identifies genes related to domestication and improvement in soybean', Nat Biotechnol, 33: 408-14. 
Table 1 Summary of the 426 Indica and 211 Japonica samples. The complete dataset of 672 samples

645

\begin{tabular}{|l|c|c|c|c|}
\hline & Subpopulation & $\begin{array}{c}\text { 3K- } \\
\text { Higgins et } \\
\text { al(2021) }\end{array}$ & $\begin{array}{c}\text { RGP(Zhou } \\
\text { et al. } \\
2020)\end{array}$ & Total \\
\hline Indica & 11 & 135 & 10 & 145 \\
\hline & 12 & 77 & 14 & 91 \\
\hline & 13 & 36 & 1 & 37 \\
\hline & 14 & 52 & 10 & 62 \\
\hline & 15 & 38 & 5 & 43 \\
\hline & Im & 41 & 7 & 48 \\
\hline
\end{tabular}

\begin{tabular}{|l|c|c|c|c|}
\hline Japonica & $\mathrm{J} 1$ & 113 & 2 & 115 \\
\hline & $\mathrm{J} 2$ & 47 & 3 & 50 \\
\hline & $\mathrm{J} 3$ & 16 & 1 & 17 \\
\hline & $\mathrm{J} 4$ & 20 & 1 & 21 \\
\hline & $\mathrm{Jm}$ & 6 & 2 & 8 \\
\hline
\end{tabular}

646

\begin{tabular}{|c|c|c|c|c|c|}
\hline & SCORE & $\mathrm{J} 1$ & $\mathrm{~J} 2$ & $\mathrm{~J} 3$ & $\mathrm{~J} 4$ \\
\hline \multirow{4}{*}{$\begin{array}{l}\frac{D}{d} \\
\stackrel{ \pm}{0} \\
\frac{\Delta}{\Delta} \\
\sim\end{array}$} & $\mathrm{J} 1$ & & 17.8 & 7.6 & 6.1 \\
\hline & $\mathrm{J} 2$ & 19.5 & & 21.6 & 6.6 \\
\hline & $\mathrm{J3}$ & 24.4 & 17.9 & & 5.9 \\
\hline & $\mathrm{J} 4$ & 46.1 & 17.5 & 17.9 & \\
\hline
\end{tabular}

\begin{tabular}{|c|c|c|c|c|c|c|}
\hline & SCORE & 11 & 12 & 13 & 14 & 15 \\
\hline \multirow{5}{*}{ 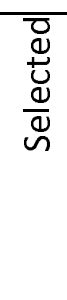 } & 11 & & 8.5 & 4.0 & 8.2 & 9.8 \\
\hline & 12 & 28.8 & & 7.0 & 15.7 & 17.3 \\
\hline & 13 & 40.2 & 24.5 & & 23.2 & 23.7 \\
\hline & 14 & 34.1 & 21.5 & 7.4 & & 18.6 \\
\hline & 15 & 63.6 & 44.6 & 18.0 & 39.2 & \\
\hline
\end{tabular}


bioRxiv preprint doi: https://doi.org/10.1101/2021.08.04.455072; this version posted August 5, 2021. The copyright holder for this preprint (which was not certified by peer review) is the author/funder, who has granted bioRxiv a license to display the preprint in perpetuity. It is made available under aCC-BY 4.0 International license.

653

654 
657

\begin{tabular}{|l|c|c|c|c|c|c|c|}
\hline & $\begin{array}{c}\text { mean } \\
\text { xp_clr } \\
\text { score }\end{array}$ & $\begin{array}{c}\text { cutoff (99 } \\
\text { percentile) }\end{array}$ & $\begin{array}{c}\text { filtered } \\
\text { regions } \\
>80000 b p\end{array}$ & $\begin{array}{c}\text { mean } \\
\text { length }\end{array}$ & $\begin{array}{c}\text { total of } \\
\text { length }\end{array}$ & $\begin{array}{c}\text { genome } \\
373,245,519 \\
\text { bp }\end{array}$ & $\begin{array}{c}\text { number of } \\
\text { genes }\end{array}$ \\
\hline J1 & 10.5 & 136 & 28 & 576,707 & $16,147,785$ & 4.3 & 2427 \\
\hline J2 & 25.9 & 256 & 23 & 726,689 & $16,713,841$ & 4.5 & 2439 \\
\hline J3 & 16.1 & 228 & 24 & 577,089 & $13,850,139$ & 3.7 & 2007 \\
\hline J4 & 27.1 & 297 & 25 & 731,341 & $18,283,522$ & 4.9 & 2643 \\
\hline I1 & 7.6 & 161 & 44 & 453,570 & $19,957,065$ & 5.3 & 3077 \\
\hline I2 & 17.2 & 275 & 41 & 550,836 & $22,584,270$ & 6.1 & 3346 \\
\hline I3 & 27.9 & 401 & 42 & 474,009 & $19,908,387$ & 5.3 & 2993 \\
\hline I4 & 20.4 & 306 & 38 & 619,404 & $23,537,343$ & 6.3 & 3465 \\
\hline I5 & 41.4 & 440 & 52 & 583,706 & $30,352,734$ & 8.1 & 4576 \\
\hline
\end{tabular}

659 


\begin{tabular}{|c|c|c|c|c|c|c|c|}
\hline Region & Chrom & Segment position (bp) & $\begin{array}{l}\wedge \mathrm{FST} I 5 \\
\text { vs } 12,13,14\end{array}$ & $\begin{array}{l}\text { number } \\
\text { of genes } \\
\text { per } \\
\text { region }\end{array}$ & $\begin{array}{l}\text { Overlap with } \\
\text { regions } \\
\text { selected in } \\
\text { other } \\
\text { subpopulations } \\
\end{array}$ & $\begin{array}{l}\text { Overlap } \\
\text { with regons } \\
\text { in other } \\
\text { studies* }\end{array}$ & Overlap with QTLs, plotted in Fig.4 (c) \\
\hline 15_1 & 1 & $5,563,164-6,569,946$ & 0.28 & 138 & $12,14, \mathrm{~J} 1, \mathrm{~J} 3, \mathrm{~J} 4$ & $1(39)$ & $\begin{array}{l}\text { Root mass (Phung et al. 2016) panicle } \\
\text { morphology (Ta et al. 2018) (a) }\end{array}$ \\
\hline 15_5 & 1 & $37,850,965-38,378,420$ & 0.64 & 84 & 11 & & $\begin{array}{l}\text { Leaf mass (Hoang, Gantet, et al. 2019) Relative } \\
\text { phosphate uptake efficiency (To et al. 2020) } \\
\text { (b) }\end{array}$ \\
\hline 15_16 & 2 & $28,191,142-29,329,745$ & 0.24 & 168 & 13 & & Jasmonate RTL (To et al. 2019) (c) \\
\hline $15 \_30$ & 5 & $386,347-1,563,159$ & 0.28 & 190 & & $3(2)$ & 9_PL (d) \\
\hline $15 \_31$ & 6 & $6,640,258-7,189,250$ & 0.17 & 80 & $|1,12| 4$, & $1(7), 3(39)$ & 12_GL (e) \\
\hline 15_32 & 6 & $7,860,166-8,418,475$ & 0.38 & 70 & $13,14, \mathrm{~J} 3$ & $1(3), 3(34)$ & Leaf length (Phung et al. 2016) (f) \\
\hline 15_33 & 6 & $19,470,641-20,499,968$ & 0.58 & 165 & 11 & & $\begin{array}{l}\text { Panicle length (Ta et al. 2018) root length and } \\
\text { number (Phung et al. 2016) (g) }\end{array}$ \\
\hline $15 \_34$ & 7 & $19,443,608-19,825,988$ & 0.19 & 54 & $11, \mathrm{~J} 4$ & & $\begin{array}{l}\text { Water content after drought (Hoang, Van } \\
\text { Dinh, et al. 2019) (h) }\end{array}$ \\
\hline $15 \_35$ & 7 & $29,030,233-29,677,525$ & 0.76 & 97 & 13 & & Root depth (Phung et al. 2016) (i) \\
\hline $15 \_36$ & 8 & $3,484,045-3,758,632$ & 0.35 & 39 & 13,14 & & Jasmonate SHL (To et al. 2019) (j) \\
\hline $15 \_37$ & 8 & $5,052,017-5,809,093$ & 0.38 & 127 & 13,14 & & Panicle branches (Ta et al. 2018) (k) \\
\hline 15_39 & 8 & $24,300,313-24,859,863$ & 0.23 & 92 & & & $\begin{array}{l}\text { Response of crown roots to phosphate (Mai et } \\
\text { al. 2020) (I) }\end{array}$ \\
\hline $15 \_48$ & 11 & $2,510,079-3,239,747$ & 0.38 & 109 & $11, \mid 4$ & $1(56)$ & $\begin{array}{l}\text { Water content after drought (Hoang, Van } \\
\text { Dinh, et al. 2019) (m) }\end{array}$ \\
\hline $15 \_49$ & 11 & $4,590,276-5,937,318$ & 0.35 & 200 & J1 & $1(3), 2(14)$ & Root number (Phung et al. 2016) (n) \\
\hline
\end{tabular}


$666 \wedge$ FST per region between the 43 samples in subpopulation I5 and the 190 samples in subpopulations I2, I3 and I4.

667 Full list of regions and further details are available in Supplementary Table S7

668

$669 *$ number of genes in brackets

6701 tall (Ind1) [Xie 2015]

$671 \quad 2$ semi-dwarf (IndII) [Xie 2015]

$672 \quad 3$ Cui 2018

673

677 Table 5: Candidate genes under selection in the Indica 15 subpopulation. Functional annotation of the 65 candidate genes and overlap with genes selected in previous

678 studies *1. ecotype differentiated genes (Lyu et al. 2014)x, 2. tall (Ind1) (Xie et al. 2015)3. semi-dwarf (IndII) (Xie et al. 2015) 4. domestication(Cui et al. 2019)

$679 \wedge$ FST per gene between the 43 samples in subpopulation I5 and the 190 samples in subpopulations I2, I3 and I4.

680 Further details are available in Supplementary Table S13

681

682

\begin{tabular}{|c|c|c|c|c|c|c|c|}
\hline Region & Gene (MSU) & $\begin{array}{c}\wedge \mathrm{FST} \\
15 \mathrm{vs} \\
12,13,14\end{array}$ & Gene function & Symbol & $\begin{array}{c}* \\
\text { Selected } \\
\text { in }\end{array}$ & impact & Ref \\
\hline
\end{tabular}




\begin{tabular}{|c|c|c|c|c|c|c|c|}
\hline 15_1 & LOC_Os01g11860 & 0.300 & $\begin{array}{l}\text { DJ-1 family protein, } \\
\text { putative, expressed }\end{array}$ & & 2 & & \\
\hline $15 \_5$ & LOC_Os01g65670 & 0.909 & $\begin{array}{l}\text { amino acid transporter, } \\
\text { putative, expressed }\end{array}$ & OsAAP6 |qPC1 & & & (Peng et al. 2014; Abbai et al. 2019) \\
\hline 15_5 & LOC_Os01g65770 & 0.936 & $\begin{array}{l}\text { expressed protein - rice } \\
\text { specfic }\end{array}$ & & & start_lost & \\
\hline $15 \_5$ & LOC_Os01g65904 & 0.788 & $\begin{array}{l}\text { expressed protein - rice } \\
\text { specfic }\end{array}$ & & & stop_gained & \\
\hline 15_5 & LOC_Os01g66030 & 0.651 & $\begin{array}{l}\text { OsMADS2 - MADS-box } \\
\text { family gene with MIKCC } \\
\text { type-box, expressed }\end{array}$ & OsMADS2 & & & (Lombardo et al. 2017) \\
\hline 15_5 & LOC_Os01g66070 & 0.445 & $\begin{array}{l}\text { PHD-finger domain } \\
\text { containing protein, } \\
\text { putative }\end{array}$ & & & & (To et al. 2019) \\
\hline 15_16 & LOC_OsO2g47310 & 0.564 & $\begin{array}{l}\text { Cyclopropane-fatty-acyl- } \\
\text { phospholipid synthase, } \\
\text { putative, expressed }\end{array}$ & VTE4 & & & (To et al. 2019) \\
\hline 15_16 & LOC_OsO2g47350 & 0.666 & $\begin{array}{l}\text { oxidoreductase, short } \\
\text { chain } \\
\text { dehydrogenase/reductase } \\
\text { family, putative, expressed }\end{array}$ & & & & (To et al. 2019) \\
\hline 15_16 & LOC_OsO2g47400 & 0.501 & $\begin{array}{l}\text { pectinacetylesterase } \\
\text { domain containing protein, } \\
\text { expressed }\end{array}$ & & & & (To et al. 2019) \\
\hline 15_16 & LOC_OsO2g47410 & 0.522 & $\begin{array}{l}\text { protein kinase, putative, } \\
\text { expressed }\end{array}$ & & & & (To et al. 2019) \\
\hline 15_16 & LOC_OsO2g47420 & 0.572 & $\begin{array}{l}\text { ATROPGEF7/ROPGEF7, } \\
\text { putative, expressed }\end{array}$ & OSROPGEF & & & (To et al. 2019) \\
\hline 15_16 & LOC_OsO2g47440 & 0.536 & $\begin{array}{l}\text { syntaxin, putative, } \\
\text { expressed }\end{array}$ & & & & (To et al. 2019) \\
\hline 15_16 & LOC_OsO2g47590 & 0.637 & $\begin{array}{l}\text { ornithine } \\
\text { carbamoyltransferase, }\end{array}$ & & & & (To et al. 2019) \\
\hline
\end{tabular}




\begin{tabular}{|c|c|c|c|c|c|c|c|}
\hline & & & putative, expressed & & & & \\
\hline I5_16 & LOC_OsO2g47660 & 0.372 & $\begin{array}{l}\text { basic helix-loop-helix, } \\
\text { putative, expressed }\end{array}$ & OsBLR1 & & & (Wang et al. 2020) \\
\hline 15_17 & LOC_OsO3g12840 & 0.477 & $\begin{array}{l}\text { Inositol } 1,3,4- \\
\text { trisphosphate } 5 / 6 \text {-kinase, } \\
\text { putative, expressed }\end{array}$ & DSM3|OsITPK2 & & stop gained & (Du et al. 2011) \\
\hline 15_17 & LOC_OsO3g13010 & 0.837 & $\begin{array}{l}\text { U-box domain containing } \\
\text { protein, expressed }\end{array}$ & TUD1|DSG1|ELF1 & & & (Sakamoto, Kitano, and Fujioka 2017) \\
\hline 15_17 & LOC_OsO3g13140 & 0.879 & $\begin{array}{l}\text { non-symbiotic hemoglobin } \\
2, \text { putative, expressed }\end{array}$ & $\mathrm{Hb} 1$ & & & $\begin{array}{l}\text { (Lira-Ruan, Ruiz-Kubli, and } \\
\text { Arredondo-Peter 2011) }\end{array}$ \\
\hline 15_17 & LOC_OsO3g14669 & 0.918 & $\begin{array}{l}\text { core histone } \\
\mathrm{H} 2 \mathrm{~A} / \mathrm{H} 2 \mathrm{~B} / \mathrm{H} 3 / \mathrm{H} 4 \text {, putative, } \\
\text { expressed }\end{array}$ & OsHAP5C & & & (Kim et al. 2016) \\
\hline $15 \_23$ & LOC_Os03g49500 & 0.719 & $\begin{array}{l}\text { ethylene receptor, } \\
\text { putative, expressed }\end{array}$ & Os-ERS1 & & & (Yu, Yau, and Yip 2017) \\
\hline $15 \_23$ & LOC_OsO3g51050 & 0.660 & $\begin{array}{l}\text { peptide transporter PTR2, } \\
\text { putative, expressed }\end{array}$ & PTR8 & 1,3 & & (Ouyang et al. 2010) \\
\hline 15_25 & LOC_OsO3g58600 & 0.844 & $\begin{array}{l}\text { PAZ domain containing } \\
\text { protein, putative, } \\
\text { expressed }\end{array}$ & MEL1 & & & (Yi et al. 2012) \\
\hline 15_25 & LOC_OsO3g58630 & 0.886 & $\begin{array}{l}\text { thioredoxin, putative, } \\
\text { expressed }\end{array}$ & OsTrxh4 & & & (Ying et al. 2017) \\
\hline $15 \_29$ & LOC_OsO4g58740 & 0.818 & $\begin{array}{l}\text { expressed protein - rice } \\
\text { specfic }\end{array}$ & & 2 & start_lost & \\
\hline $15 \_29$ & LOC_OsO4g58750 & 0.815 & $\begin{array}{l}\text { protein kinase family } \\
\text { protein, putative, } \\
\text { expressed }\end{array}$ & OsBSK3 & 2 & & (Zhang et al. 2016) \\
\hline $15 \_29$ & LOC_OsO4g58780 & 0.806 & $\begin{array}{l}\text { pentatricopeptide repeat } \\
\text { protein, putative, } \\
\text { expressed }\end{array}$ & WSL5|OsPPR4 & 2 & & (Liu et al. 2018) \\
\hline
\end{tabular}




\begin{tabular}{|c|c|c|c|c|c|c|c|}
\hline 15_29 & LOC_OsO4g58870 & 0.813 & $\begin{array}{l}\text { exo70 exocyst complex } \\
\text { subunit, putative, } \\
\text { expressed }\end{array}$ & & & splice_acceptor_variant\&intron_variant & (Tu et al. 2015) \\
\hline 15_29 & LOC_OsO4g58880 & 0.826 & $\begin{array}{l}\text { exo70 exocyst complex } \\
\text { subunit, putative, } \\
\text { expressed }\end{array}$ & RLS2|OsEXO70A1 & & & (Tu et al. 2015) \\
\hline 15_30 & LOC_Os05g02260 & 0.617 & interacts with OsMPK1 & bip130 & & stop_gained & (Zhou et al. 2019) \\
\hline 15_31 & LOC_Os06g12450 & 0.360 & $\begin{array}{l}\text { soluble starch synthase } 2- \\
3 \text {, chloroplast precursor, } \\
\text { putative, expressed }\end{array}$ & ALK|SSIIa & 4 & & (Zhang et al. 2011) \\
\hline 15_32 & LOC_Os06g14620 & 0.471 & $\begin{array}{l}\text { ribonucleoside- } \\
\text { diphosphate reductase } \\
\text { small chain, putative, } \\
\text { expressed }\end{array}$ & $S D L / R N R S 1$ & 4 & & (Qin et al. 2017) \\
\hline 15_33 & LOC_Os06g34360 & 0.959 & $\begin{array}{l}\text { zinc finger, C3HC4 type } \\
\text { domain containing protein, } \\
\text { expressed }\end{array}$ & & & & (Zang et al. 2016) \\
\hline 15_33 & LOC_Os06g34650 & 0.948 & $\begin{array}{l}\text { zinc finger, } \mathrm{C} 3 \mathrm{HC} 4 \text { type } \\
\text { domain containing protein, } \\
\text { expressed }\end{array}$ & & & & (Zang et al. 2016) \\
\hline 15_33 & LOC_Os06g33520 & 0.509 & $\begin{array}{l}\text { DEAD/DEAH box helicase, } \\
\text { putative, expressed }\end{array}$ & OsABP & & & (Macovei et al. 2012) \\
\hline 15_35 & LOC_Os07g48560 & 0.927 & $\begin{array}{l}\text { homeobox domain } \\
\text { containing protein, } \\
\text { expressed }\end{array}$ & WOX11 & & & (Zhang et al. 2018) \\
\hline 15_35 & LOC_Os07g48640 & 0.953 & $\begin{array}{l}\text { short-chain } \\
\text { dehydrogenase/reductase, } \\
\text { putative, expressed }\end{array}$ & OsSDR & & & (Kim et al. 2009) \\
\hline $15 \_35$ & LOC_Os07g48680 & 0.955 & $\begin{array}{l}\text { zinc finger, C3HC4 type } \\
\text { domain containing protein, } \\
\text { expressed }\end{array}$ & & & & (Zang et al. 2016) \\
\hline $15 \_35$ & LOC_Os07g48750 & 0.920 & $\begin{array}{l}\text { alpha-N- } \\
\text { arabinofuranosidase, } \\
\text { putative, expressed }\end{array}$ & OsARAF1 & & & (Sumiyoshi et al. 2013) \\
\hline
\end{tabular}




\begin{tabular}{|c|c|c|c|c|c|c|c|}
\hline 15_35 & LOC_Os07g48780 & 0.907 & $\begin{array}{l}\text { OsCam1-2 - Calmodulin, } \\
\text { expressed }\end{array}$ & $\begin{array}{l}\text { OsCam1- } \\
2 \text { OsCam1 }\end{array}$ & & & $\begin{array}{l}\text { (Saeng-ngam et al. 2012), } \\
\text { (Yuenyong et al. 2018) }\end{array}$ \\
\hline $15 \_35$ & LOC_Os07g48820 & 0.901 & $\begin{array}{l}\text { transcription factor, } \\
\text { putative, expressed }\end{array}$ & OsbZIP63|OsNIF1 & & & $\begin{array}{l}\text { (Delteil et al. 2012), (Vemanna et } \\
\text { al. 2019) }\end{array}$ \\
\hline 15_35 & LOC_Os07g48830 & 0.931 & $\begin{array}{l}\text { glycosyl transferase } 8 \\
\text { domain containing protein, } \\
\text { putative, expressed }\end{array}$ & OsGols2|wsi76 & & & (Mukherjee et al. 2019) \\
\hline 15_35 & LOC_Os07g48920 & 0.916 & $\begin{array}{l}\text { aldehyde dehydrogenase, } \\
\text { putative, expressed }\end{array}$ & OsALDH22 & & & (Yang et al. 2012) \\
\hline 15_36 & LOC_Os08g06370 & 0.014 & $\begin{array}{l}\text { MYB family transcription } \\
\text { factor, putative, expressed }\end{array}$ & & & & (To et al. 2019) \\
\hline 15_37 & LOC_Os08g09110 & 0.904 & $\begin{array}{l}\text { NB-ARC domain containing } \\
\text { protein, expressed }\end{array}$ & & & stop_gained & \\
\hline $15 \_37$ & LOC_Os08g09190 & 0.286 & $\begin{array}{l}\text { auxin efflux carrier } \\
\text { component, putative, } \\
\text { expressed }\end{array}$ & OsPILS2 & & & (Ta et al. 2018) \\
\hline 15_39 & LOC_Os08g39100 & 0.239 & $\begin{array}{l}\text { protein phosphatase } 2 \mathrm{C} \text {, } \\
\text { putative, expressed }\end{array}$ & OsPP2C66 & & & (Mai et al. 2020) \\
\hline 15_39 & LOC_Os08g38990 & 0.202 & WRKY3O, expressed & OsWRKY30 & & & (Mai et al. 2020) \\
\hline 15_41 & LOC_Os09g28280 & 0.654 & $\begin{array}{l}\text { gibberellin receptor } \\
\text { GID1L2, putative, } \\
\text { expressed }\end{array}$ & & 4 & & \\
\hline 15_41 & LOC_Os09g28840 & 0.654 & $\begin{array}{l}\text { OsSCP43 - Putative Serine } \\
\text { Carboxypeptidase } \\
\text { homologue, expressed }\end{array}$ & & & & \\
\hline 15_42 & LOC_Os09g30340 & 0.971 & $\begin{array}{l}\text { photosystem I reaction } \\
\text { center subunit, chloroplast } \\
\text { precursor, putative, } \\
\text { expressed }\end{array}$ & PSAG & & & (Park et al. 2012) \\
\hline 15_42 & LOC_Os09g30360 & 0.973 & $\begin{array}{l}\text { caffeoyl-CoA O- } \\
\text { methyltransferase, }\end{array}$ & & & & \\
\hline
\end{tabular}




\begin{tabular}{|c|c|c|c|c|c|c|c|}
\hline & & & putative, expressed & & & & \\
\hline $15 \_42$ & LOC_Os09g30380 & 0.966 & $\begin{array}{l}\text { AP005392-AK108636 - } \\
\text { NBS/LRR genes that are S- } \\
\text { rich,divergent TIR, } \\
\text { divergent NBS, expressed }\end{array}$ & & & & \\
\hline $15 \_42$ & LOC_Os09g30400 & 0.954 & WRKY90, expressed & OsWRKY8O & & & (Peng et al. 2016) \\
\hline 15_42 & LOC_Os09g30410 & 0.961 & expressed protein & & & & \\
\hline 15_42 & LOC_Os09g31019 & 0.942 & $\begin{array}{l}\text { ubiquitin fusion protein, } \\
\text { putative, expressed }\end{array}$ & & & & (Chen et al. 2017) \\
\hline $15 \_47$ & LOC_Os10g35260 & 0.703 & $\begin{array}{l}\text { Rf1, mitochondrial } \\
\text { precursor, putative, } \\
\text { expressed }\end{array}$ & & 3 & & \\
\hline 15_47 & LOC_Os10g35540 & 0.783 & $\begin{array}{l}\text { hydrolase, alpha/beta fold } \\
\text { family domain containing } \\
\text { protein, expressed }\end{array}$ & & 3 & & \\
\hline 15_47 & LOC_Os10g35560 & 0.692 & expressed protein & OsSFR6 & 3 & & (de Freitas et al. 2019) \\
\hline 15_47 & LOC_Os10g35604 & 0.661 & expressed protein & & 3 & stop_gained & \\
\hline 15_47 & LOC_Os10g35640 & 0.700 & $\begin{array}{l}\text { Rf1, mitochondrial } \\
\text { precursor, putative, } \\
\text { expressed }\end{array}$ & $\mathrm{Rf1b}$ & 3 & & \\
\hline $15 \_48$ & LOC_Os11g05640 & 0.367 & $\begin{array}{l}\text { bZIP transcription factor } \\
\text { domain containing protein, } \\
\text { expressed }\end{array}$ & $\begin{array}{l}\text { OsZIP- } \\
\text { 2a|OsbZIP80 }\end{array}$ & 2 & & (Nijhawan et al. 2008) \\
\hline $15 \_48$ & LOC_Os11g06390 & 0.746 & actin, putative, expressed & OSACTIN2 & 2 & & \\
\hline 15_48 & LOC_Os11g06410 & 0.841 & $\begin{array}{l}\text { homeodomain, putative, } \\
\text { expressed }\end{array}$ & SAB18 & 2 & & \\
\hline
\end{tabular}




\begin{tabular}{|c|c|c|c|c|c|c|c|}
\hline 15_48 & LOC_Os11g06490 & 0.715 & $\begin{array}{l}\text { ribosome inactivating } \\
\text { protein, putative, } \\
\text { expressed }\end{array}$ & & & & \\
\hline $15 \_49$ & LOC_Os11g09360 & 0.919 & $\begin{array}{l}\text { OsFBX398 - F-box domain } \\
\text { containing protein, } \\
\text { expressed }\end{array}$ & OsFBX398 & & splice_donor_variant\&intron_variant & (Jain et al. 2007) \\
\hline $15 \_49$ & LOC_Os11g10070 & 0.721 & $\begin{array}{l}\text { transcriptional corepressor } \\
\text { SEUSS, putative, expressed }\end{array}$ & OsSEU2 & 3 & splice_donor_variant\&intron_variant & (Tanaka, Toriba, and Hirano 2017) \\
\hline
\end{tabular}

684

685

686

687 
Fig. 1 XP-CLR scores and regions under selection.

689 (a) Selected regions for the five Indica subpopulations covering $5.4 \%, 6.1 \%, 5.3 \%, 6.3 \%$ and $8.1 \%$ of the

690 genome for I1, I2, I3, I4 and I5 respectively. Centromeric regions are shown as $100 \mathrm{~kb}$ regions in dark grey.

691 (b) Selected region for the four Japonica subpopulations covering $4.3 \%, 4.5 \%, 3.7 \%$ and $4.9 \%$ of the genome

692 for J1, J2, J3 and J4 respectively.

693

\section{Fig. 2 Gene Ontology overrepresentation}

Fig. 3 Selection sweeps in the Indica I5 subpopulation compared to the other Vietnamese subpopulations

XP-CLR scores in 100,000 bp sliding windows are plotted along the 12 chromosomes, showing selection in the

I5 subpopulation compared to (a) I2, (b) I2, (c) I3, (d) I4. The horizontal dashed line indicates the threshold XP-

CLR score of 440 for determining selected regions. (e) $F_{S T}$ in 100,000 bp sliding windows for the 43 samples in genetic diversity ( $\Pi$ ) in 100,000 bp sliding windows for the 43 samples in the I5 subpopulation. The vertical lines show the position of the 52 selected regions.

Fig. 4 Vietnamese QTLs and their overlap with selected regions in the 15 subpopulation. QTLs from 8 published studies (Phung et al. 2016; Ta et al. 2018; To et al. 2019; Hoang, Gantet, et al. 2019; Hoang, Van Dinh, et al. 2019; Mai et al. 2020; To et al. 2020) (Higgins et al.) are plotted along each chromosome together with the 52 regions selected in the $I 5$ subpopulation. The fourteen selected regions which overlap with at least one QTL are highlighted, the letters refer to the details shown in Table 2

Fig. 5 Allele Plots for "High impact" SNPs within eight candidate genes. Bar plots showing the base count

713 IUPAC ambiguity codes.

\section{Supplementary tables}

717 Supplementary Table S1 Reciprocal difference between comparisons for each subpopulation pair 
719 Supplementary Table S2. Summary of XP-CLR comparisons for the Indica and Japonica subpopulations.

720 Detailing the XP-CLR mean, cut off and number of regions for each comparison.

721

722 Supplementary Table S3. List of genes selected in each subpopulation.

723

724 Supplementary Table S4. Overlap of the selected regions in Indica subpopulations with QTL found in

725 Vietnamese rice datasets.

726

727 Supplementary Table S5. Overlap of the selected regions in Japonica subpopulations with QTL found in

728 Vietnamese rice datasets.

729

730 Supplementary Table S6. Gene Ontology enrichment for each selected region.

731

732 Supplementary Table S7. List of 52 regions selected in the Indica I5 subpopulation.

733

734 Supplementary Table S8. Annotation of I5 selected regions using PhytoMine. Enrichment analysis for protein

domain and Meta-Cyc pathway using PhytoMine.

736

Supplementary Table S9. List of genes selected in each region for the Indica I5 subpopulation.

Supplementary Table S10. List of all genes selected in I5 subpopulation. Detailing MSU and RAP gene ID,

740 annotation and enrichment in Phytomine, high impact SNPs and mean $\mathrm{F}^{\mathrm{st}}$

741

742 Supplementary Table S11. Details of QTLs within the fourteen overlapping regions.

744 Supplementary Table S12. List of 21 genes related to salt tolerance selected in the I5 subpopulation.

746 Supplementary Table S13. Details of 64 candidate genes.

748 Supplementary Table S14. Details of "High impact" SNPs within eight candidate genes. 
752 Fig. S1 Chromosome plots of regions selected in each Indica subpopulation showing the regions selected

753 against each individual subpopulation and the shaded final selected regions which were selected against three

754 subpopulations.

755 a) 44 regions selected in I1, b) 41 regions selected in I2, c) 42 regions selected in I3, d) 38 regions selected in I4,

756 e) 52 regions selected in I5

757

758 Fig. S2 Chromosome plots of regions selected in each Japonica subpopulation showing the regions selected

759 against each individual subpopulation and the shaded final selected regions which were selected against two

760 subpopulations.

761 a) 28 regions selected in $\mathrm{J} 1$, b) 23 regions selected in $\mathrm{J} 2$, c) 24 regions selected in J3, d) 25 regions selected in J4

762

763 Fig. S3 Range of sizes for selected regions in (a) five Indica subpopulations and (b) four Japonica

764 subpopulations

765

766 Fig. S4 Upset plots for overlap of genes in selected regions for (a) all nine subpopulations, (b) five Indica 
bioRxiv preprint doi: https://doi.org/10.1101/2021.08.04.455072; this version posted August 5, 2021. The copyright holder for this preprint (which was not certified by peer review) is the author/funder, who has granted bioRxiv a license to display the preprint in perpetuity. It is made available under aCC-BY 4.0 International license.

771 

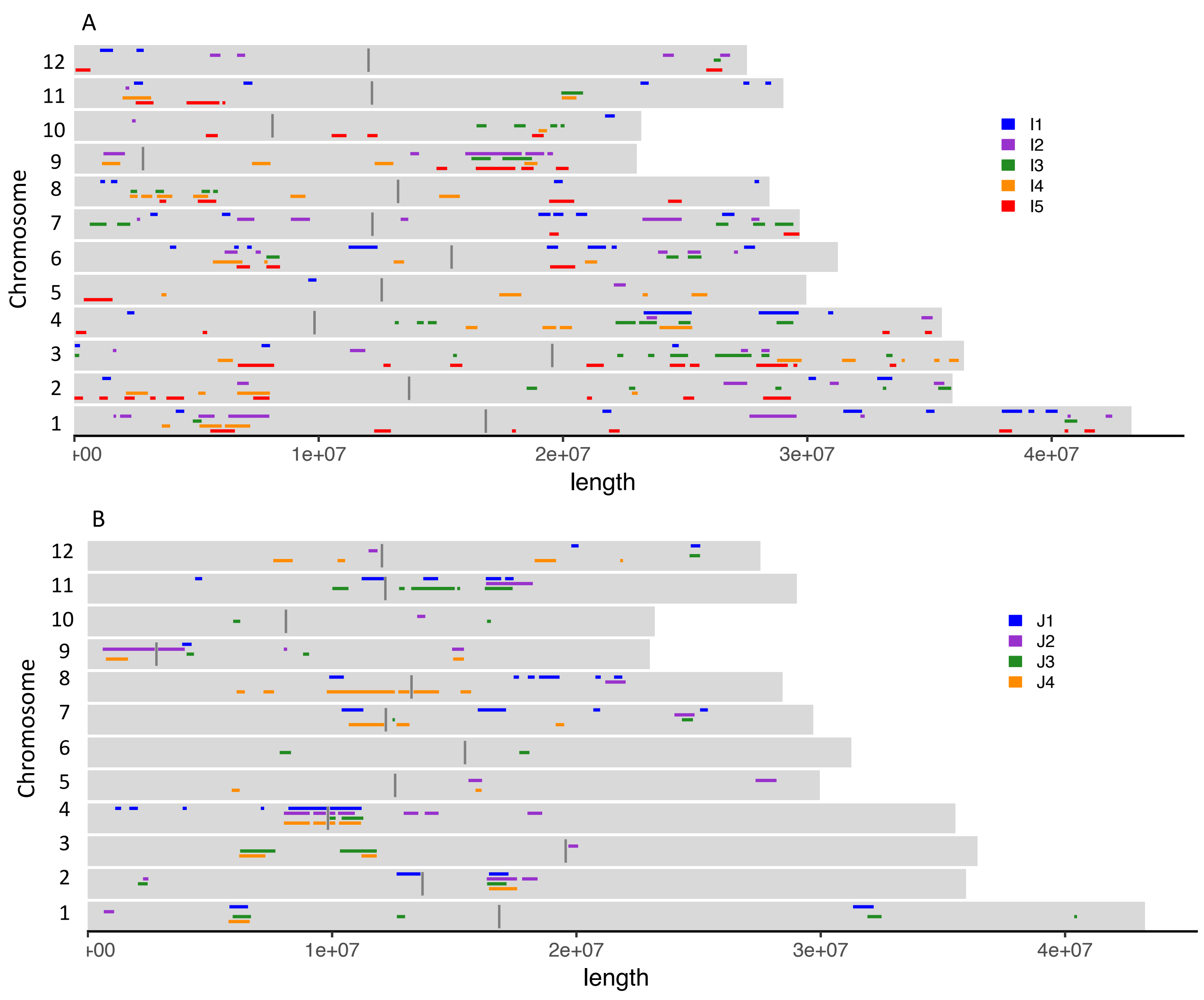


\section{GO TERMS}

Anatomical Structure Morphogenesis

Biosynthetic Process

Carbohydrate Metabolic Process

Catabolic Process

Cell Communication

Cell Death

Cell Differentiation

Cellular Component Organization

Cellular Process

Cellular Protein Modification Process

Dna Metabolic Process

Embryo Development

Flower Development

Generat. Prec.Metabolites \& energy Lipid Metabolic Process Metabolic Process

Multicellular Organism Development Nucleobase-cont. Compound Metab. Photosynthesis Pollination

Post-Embryonic Development Protein Metabolic Process Reproduction

Response to Abiotic Stimulus

Response to Biotic Stimulus Response to Endogenous Stimulus Response To Stress Secondary Metabolic Process Signal Transduction

Signaling Translation Transport

\section{$\begin{array}{llllllllll} & \text { I1 } & \text { I2 } & \text { I3 } & \text { I4 } & \text { I5 } & \text { J1 } & \text { J2 } & \text { J3 } & \text { J4 }\end{array}$}

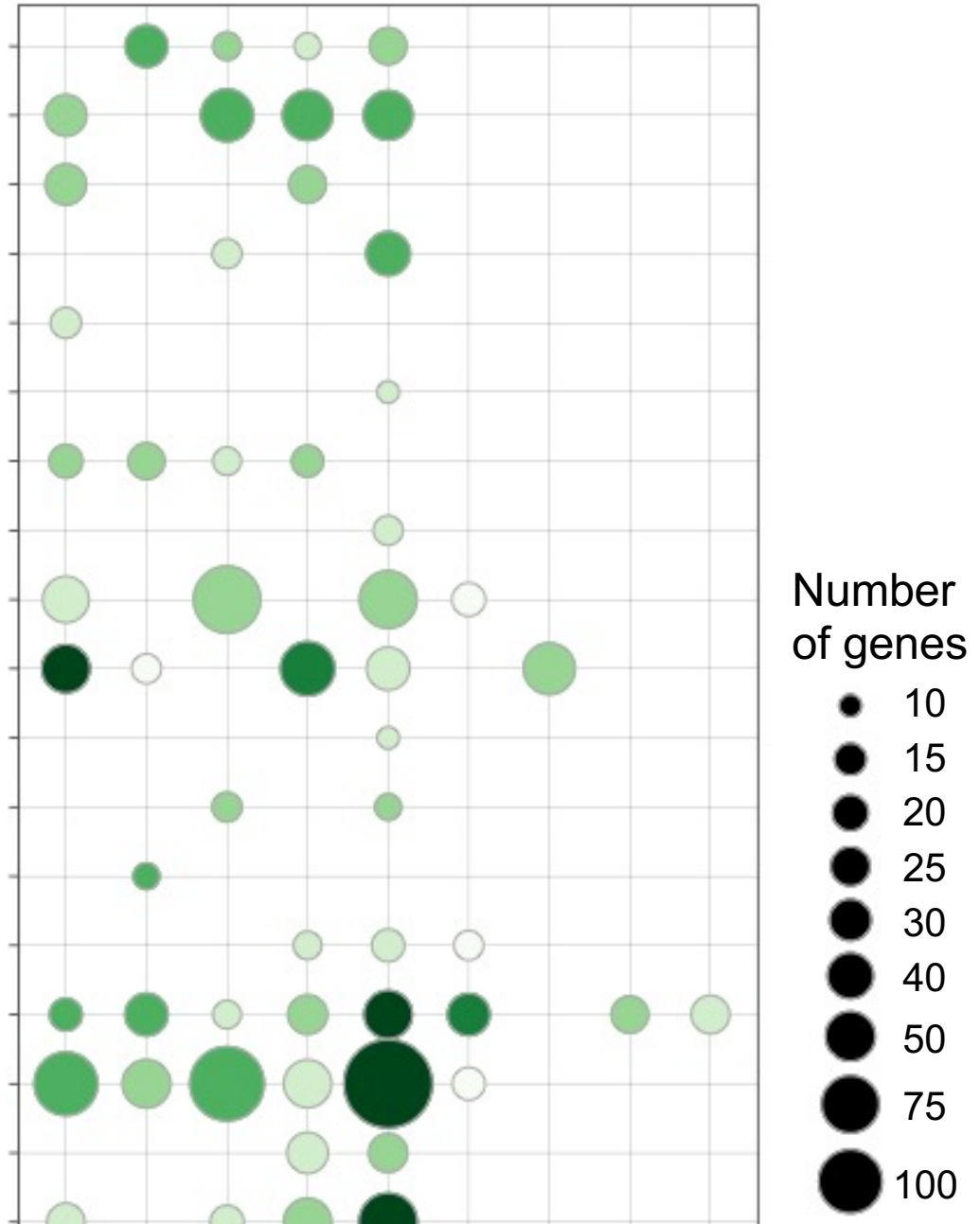

Number of regions

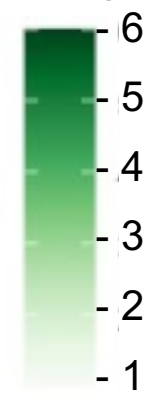



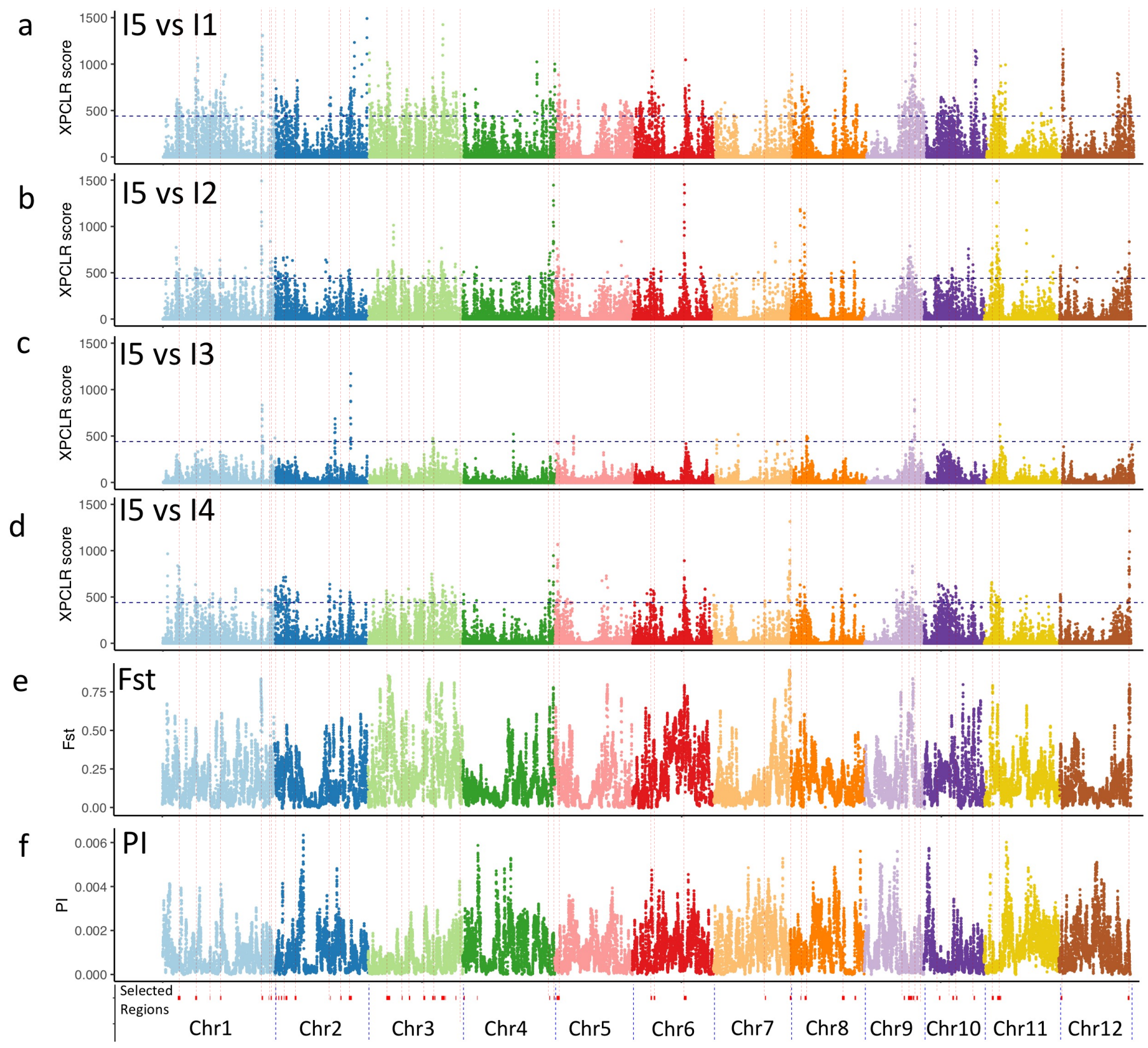


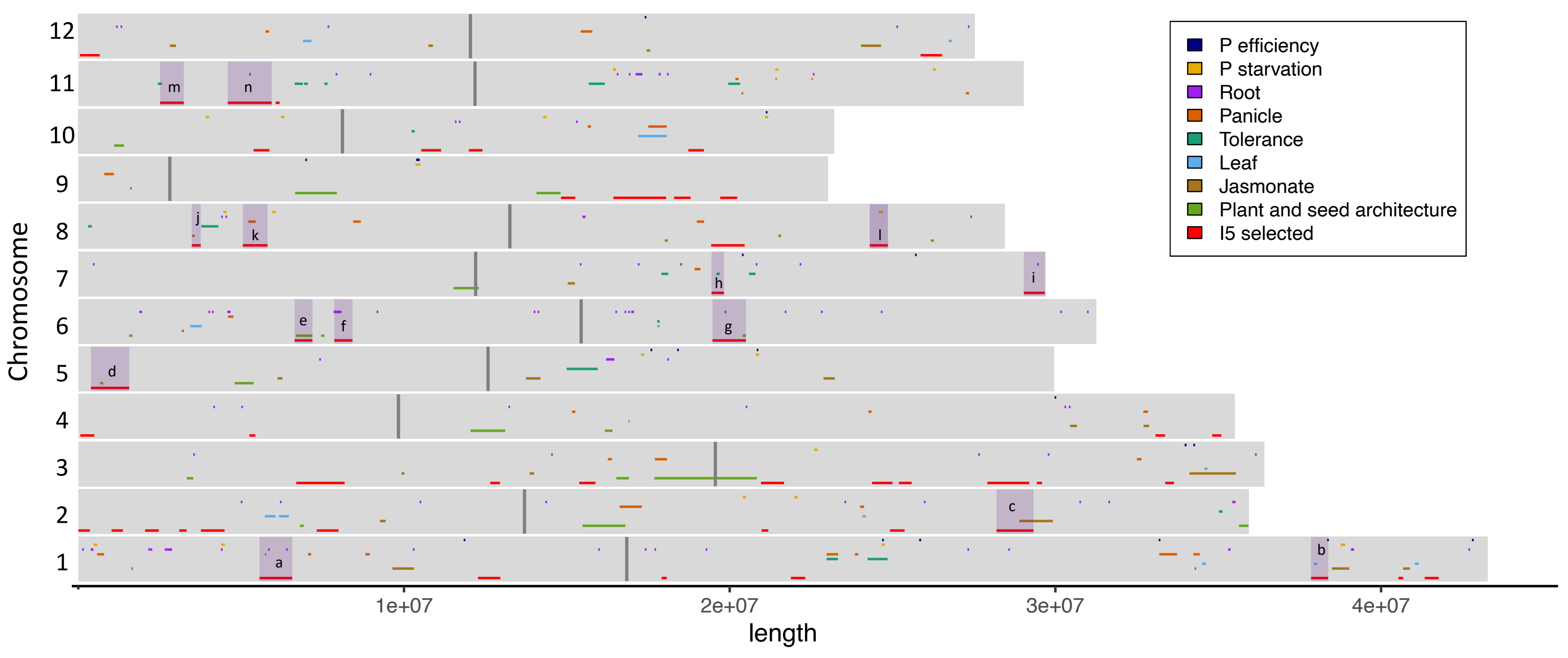



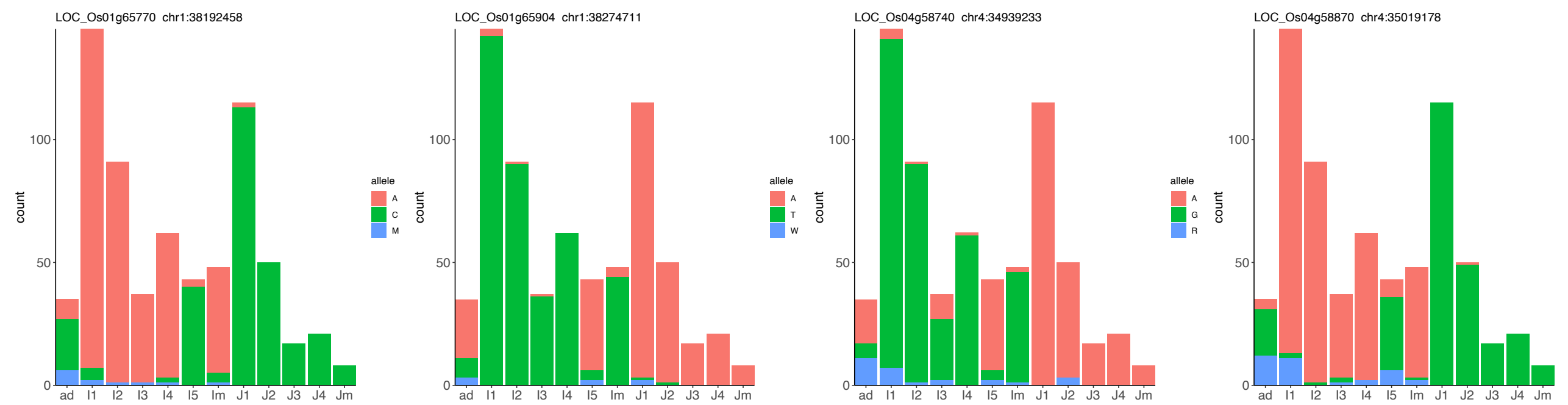

allele
$-\stackrel{A}{A}$
${ }^{\circ}$
$M$
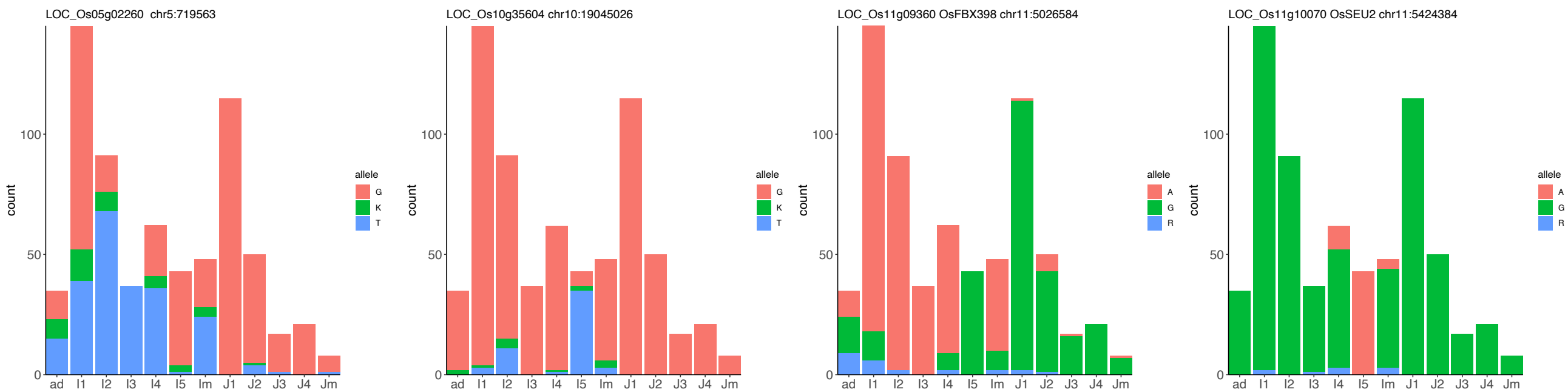